\title{
IL-9 and its receptor are predominantly involved in the pathogenesis of UC
}

\author{
Nancy Nalleweg, ${ }^{1}$ Mircea Teodor Chiriac, ${ }^{1}, 2,3$ Eva Podstawa, ${ }^{1}$ Christian Lehmann, ${ }^{4}$ \\ Tilman T Rau, ${ }^{5}$ Raja Atreya, ${ }^{1}$ Ekaterina Krauss, ${ }^{1}$ Gheorghe Hundorfean, ${ }^{1}$ \\ Stefan Fichtner-Feigl, ${ }^{6}$ Arndt Hartmann, ${ }^{5}$ Christoph Becker, ${ }^{1}$ Jonas Mudter ${ }^{1,7}$
}

\begin{abstract}
- Additional material is published online only. To view please visit the journal online (http://dx.doi.org/10.1136/ gutjnl-2013-305947).

For numbered affiliations see end of article.
\end{abstract}

\section{Correspondence to}

Dr Jonas Mudter, Sana Clinic Ostholstein, Hospitalstraße 22, Eutin 23701, Germany; jonas. mudter@sana.de

NN and MTC contributed equally.

Received 26 August 2013 Revised 20 May 2014 Accepted 22 May 2014 Published Online First 23 June 2014
CrossMark

To cite: Nalleweg N,
Chiriac MT, Podstawa $\mathrm{E}_{\text {, }}$
et al. Gut 2015;64:
743-755.

\section{ABSTRACT}

Objective Several pathogenic roles attributed over the past two decades to either Thelper (Th)1 or Th2 cells are increasingly becoming associated with interleukin (IL)-17 and most recently IL-9 signalling. However, the implication of IL-9 in IBD has not been addressed so far. Design We investigated the expression of IL-9 and IL-9R by using peripheral blood, biopsies and surgical samples. We addressed the functional role of IL-9 signalling by analysis of downstream effector proteins. Using Caco-2 cell monolayers we followed the effect of IL-9 on wound healing.

Results IL-9 mRNA expression was significantly increased in inflamed samples from patients with UC as compared with controls. $\mathrm{CD}^{+} \mathrm{T}$ cells were major IL-9-expressing cells and some polymorphonuclear leucocytes (PMN) also expressed IL-9. IL-9 was co-localised with the key Th9 transcription factors interferon regulatory factor 4 and PU.1. Systemically, IL-9 was abundantly produced by activated peripheral blood lymphocytes, whereas its receptor was overexpressed on gut resident and circulating PMN. IL-9 stimulation of the latter induced IL-8 production in a dose-dependent manner and rendered PMN resistant to apoptosis suggesting a functional role for IL-9R signalling in the propagation of gut inflammation. Furthermore, IL-9R was overexpressed on gut epithelial cells and IL-9 induced STAT5 activation in these cells. Moreover, IL-9 inhibited the growth of Caco-2 epithelial cell monolayers in wound healing experiments.

Conclusions Our results provide evidence that IL-9 is predominantly involved in the pathogenesis of UC suggesting that targeting IL-9 might become a therapeutic option for patients with UC.

\section{INTRODUCTION}

UC, the most common form of IBD, is a chronic condition in which the overreacting immune system drives a sustained epithelial damage of the gut in response to microbial and environmental factors in a genetically predisposed individual. ${ }^{12}$ Our understanding of IBD pathogenesis has profited from major advances in experimental animal models of the disease and sequence analysis of susceptibility genes. ${ }^{1-4}$ Based on patient data and the murine oxazolone-induced colitis model, that drives a Th2-like response, it has been proposed that epithelial barrier damage in UC is driven by a T helper cell (Th)2-like phenotype and interleukin (IL)-13 has been associated with disease pathogenesis in UC. ${ }^{5} 6$

\section{Significance of this study}

What is already known on this subject?

- IBD is a chronic life-threatening condition characterised by an overreacting immune response in genetically susceptible individuals.

- Disease pathogenesis in UC, one of the two major forms of IBD, has been attributed to an altered Th2/Th17 response.

- Our previous work suggested a critical role for interferon regulatory factor 4 (IRF4) in controlling IL-17-dependent gut inflammation.

- IRF4 and PU.1 have been recently identified as master transcription factors of the newly defined Th9 cells.

What are the new findings?

- IL-9 was highly expressed in UC correlating with disease activity; the main source of IL-9 were $\mathrm{CD}^{+} \mathrm{T}$ cells and multicolour immunofluorescence stainings demonstrated the co-localisation of IL-9 with the Th9 transcription factors IRF4 and PU.1 but not with the cytokines IL-4 or IL-10.

- Stimulated peripheral blood lymphocytes from patients with UC produced significantly more IL-9 than control cells.

- Peripheral blood and lamina propria infiltrating polymorphonuclear leucocytes expressed the IL-9R; stimulation of blood polymorphonuclear leucocytes with IL-9 resulted in a dose-dependent production of IL-8 that (1) could be blocked by anti-IL-9R antibodies and (2) was accompanied by increased resistance of polymorphonuclear leucocytes to apoptosis.

- IL-9 stimulation of freshly isolated IL-9R-overexpressing epithelial cells led to STAT5 activation; anti-IL-9R blockade could prevent the IL-9-induced growth delay of Caco-2 cell monolayers in wound healing assays.

\section{How might it impact on clinical practice in} the foreseeable future?

- IL-9 could represent a valuable tool in assessing disease severity and its signalling pathways may become novel therapeutic targets in UC.

The identification of the Th17 lineage of $\mathrm{T}$ helper cells at the beginning of the century ${ }^{7}$ has challenged the Th1-Th2 paradigm proposed by 
Mosmann and Coffman in $1986^{8} 9$ opening new avenues for dissecting molecular patterns in cellular immunology. It was soon demonstrated that Th17 cells were critically involved in host defence and disease pathogenesis in tissues like the gut, the lung and the brain. ${ }^{710}$ At present, it is accepted that UC pathogenesis is driven by a modified Th2 response mixed with a Th17 cell-sustained inflammation. ${ }^{10}{ }^{11}$ Even more recently however, new subsets of Th cells, for example, Th $9^{12}$ and Th22, ${ }^{13}$ have been defined but their roles in gut pathology remained unaddressed.

IL-9 has been discovered as a potent growth factor for T cell lines and mast cells and its role in allergic and asthmatic conditions has been largely characterised over the past decade. ${ }^{14}{ }^{15}$ Initially viewed as a Th2 cytokine, and thereafter associated with Th17 responses, IL-9 has been recently proposed to be the defining cytokine for a new lineage of CD4 T cells, the Th9 cells, which additionally produce high levels of IL-10 but none of the Th1-specific, Th2-specific and Th17-specific cytokines. ${ }^{16} 17$ The signalling of the novel Th9 cells has been linked to the transcriptional programmes of STAT $6,{ }^{16-18}$ interferon regulatory factor (IRF) $4^{19}$ and PU.1. ${ }^{20}$ Nevertheless, our previous studies demonstrated a critical role for IRF4 in the pathogenesis of IBD. ${ }^{21} 22$

In the present study, we investigated the role of IL-9 and the Th9 transcription factors IRF4 and PU.1 in UC. Our findings suggest that IL-9 is predominantly involved in the pathogenesis of the disease.

\section{MATERIALS AND METHODS}

The collection of human samples was approved by the local Ethical Committee and the Review Board of the University of Erlangen-Nuremberg, and each patient gave written informed consent (number 4032/KFO/2011, 4032/2009). Materials and methods are available as online supplementary file 1 .

\section{RESULTS \\ IL-9 mRNA is significantly overexpressed in mucosal biopsies of the inflamed gut in UC}

We first assessed colonic biopsies from patients with UC and controls by quantitative real-time PCR for IL-9 mRNA expression. In these studies, mucosal inflammation was classified according to previously described criteria: inflammation score (IS)0 (absent inflammation)-IS3 (severe inflammation). ${ }^{23}$ It was found that the level of IL-9 mRNA expression increased with increasing IS in UC (figure 1A). In addition, the levels of other proinflammatory cytokines (such as IL-17A and IL-6) were also increased in severely inflamed UC mucosa. However, IL-9 levels in the ileum and colon of patients with Crohn's disease were not significantly upregulated (figure 1A). Moreover, in contrast to IL-9, mRNA levels for IL-4, IL-6, IL-10, IL-13, IL-17A, IL-21, IFN $\gamma$, TGF- $\beta$ and TNF $\alpha$ were detected in patients with UC with lower inflammation and, albeit at lower levels, also in controls (figure 1A). Highest correlations between IL-9 mRNA levels and levels of IL-6 ( $R=0.49 ; \mathrm{p}<0.001)$, IL-13 ( $\mathrm{R}=0.47$; $\mathrm{p}<0.001)$ and IL-17A $(\mathrm{R}=0.47 ; \mathrm{p}<0.001)$ were observed (figure 1B). In addition, a correlation between the expression levels of the inflammatory protein marker S100A8 and IL-9 was noted $(\mathrm{R}=0.57 ; \mathrm{p}<0.001$; figure $1 \mathrm{~B})$.

\section{$\mathrm{CD}^{+} \mathrm{T}$ cells are key IL-9-expressing cells in the inflamed gut of patients with UC}

Next, we systematically focused on investigating mildly (ie, IS1) as well as severely (ie, IS3) inflamed material along with control samples. Paraffin sections of gut specimens from patients with
UC with mild and severe inflammation and non-inflammatory controls were first stained with antibodies against IL-9 (figure 2A). Quantification of these data showed a significantly increased number of IL-9-expressing cells in severe versus mild inflammation as well as in both groups versus the control group (figure 2B). Furthermore, two-colour immunofluorescence stainings of paraffin sections revealed that patients with severe inflammation had significantly increased numbers of $\mathrm{CD}^{+}$ IL-9-expressing cells compared with patients with mild inflammation and the control group, respectively (figure $2 \mathrm{C}, \mathrm{D}$ ). Although $\mathrm{CD}^{+}$cells accounted for more than $75 \%$ of the IL-9-expressing cells in the inflamed gut (figure 2E), some IL-9-expressing cells were $\mathrm{CD}^{-}{ }^{-}$. To address the nature of these cells, we stained gut sections with IS3 for IL-9 and myeloperoxidase, a specific marker for polymorphonuclear leucocytes $(\mathrm{PMN})$ that often dominate the acute inflammatory infiltrate in UC. Our results showed that myeloperoxidase positive PMN can express IL-9 in UC (see online supplementary figure S1A).

\section{Upregulation of the key Th9 transcription factors IRF4 and PU. 1 in UC}

IL-9 expression by Th9 cells was previously reported to be dependent on the transcription factors IRF $4{ }^{19}$ and PU. $1 .{ }^{20}$ We found that mRNA expression levels of IRF4 and PU.1 generally increased with increasing inflammation in UC (figure 3A). Moreover, patients with severe disease expressed significantly more IRF4 and PU.1 compared with controls which showed lower expression. Within individual cells IL-9 co-localised with each of the two key transcription factors of the Th9 cells, namely IRF4 and PU.1, respectively (figure 3B, C). The number of IRF4 ${ }^{+}$IL-9-expressing cells and PU. $1^{+}$IL-9-expressing cells was significantly increased in patients with severe (ie, IS3) versus mild (ie, IS1) disease as well as in both groups versus controls (figure $3 \mathrm{~B}, \mathrm{C}$ ).

To functionally address the role of IRF4 for IL-9 production in UC, we isolated peripheral blood lymphocytes of patients with UC and cultured them under Th9 polarising conditions. We found that compared with non-polarised cells which only had marginal levels of IL-9 expression, as many as 6\% of the Th9 polarised cells expressed IL-9 in patients with UC (figure 4A). Moreover, we observed that $25 \%$ of the polarised $\mathrm{CD}^{+}{ }^{-} \mathrm{IRF}^{+}{ }^{+}$cells expressed IL-9 (figure 4A). We additionally performed three-colour immunofluorescence stainings on IS3 gut biopsies and found that IL-9 and IRF4 were coexpressed in $\mathrm{CD}^{+}$cells (figure 4B), consistent with the idea that IRF4 acts as a key transcription factor for the generation of IL-9 in the inflamed gut of patients with UC. IL-9 has been previously found to be coexpressed with IL-10 in murine $\mathrm{CD}^{+}{ }^{+} \mathrm{T}$ cells ${ }^{16}$ ${ }^{17}$ or with IL-4 in murine invariable natural killer (NK)T cells, ${ }^{24}$ respectively. To address the expression profile of these cytokines in IL-9-expressing cells, we stained freshly isolated lamina propria cells from inflamed UC tissue with antibodies to CD3, Vo24-J 18 (invariant NKT cells marker), IL-4, IL-9 and IL-10. Our results demonstrated that IL-9 and IL-10 were produced by distinct $\mathrm{CD}^{+}$cells (figure 4C). Moreover, invariant NKT cells did not produce IL-9 (figure 4C). Taken together these results suggest that in patients with UC, IL-9 is mainly produced by $\mathrm{CD}^{+}$cells that do not coexpress IL-10 or IL-4.

\section{Human IL-9-secreting peripheral blood lymphocytes express the gut homing markers $\alpha 4$ and $\beta 7$ integrin}

To investigate the potential of peripheral blood lymphocytes to produce IL-9 along with other cytokines whose levels have been found to be altered in UC (eg, IL-4, IL-10, IL-13, IL17A/F, 


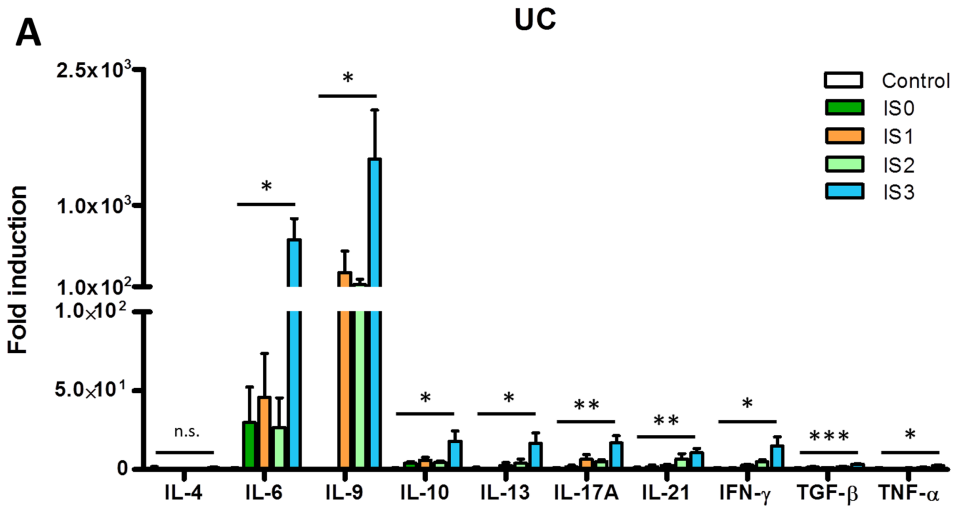

IL-9

B Correlation of IL-9 and IL-6

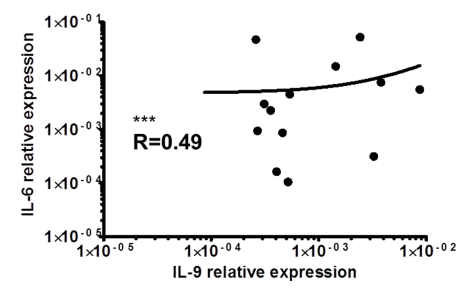

Correlation of IL-9 and IL-4
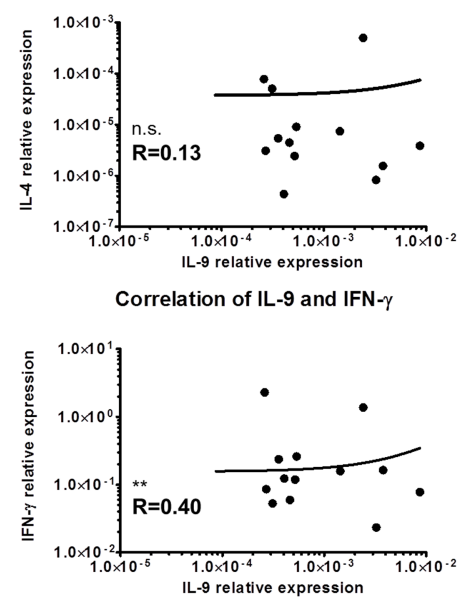

Correlation of IL-9 and S100A8

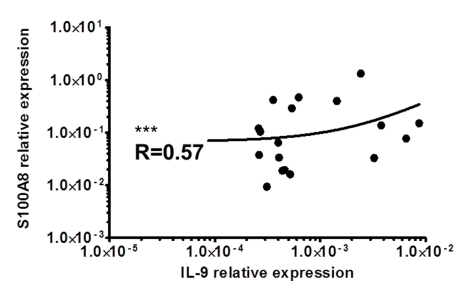

Correlation of IL-9 and IL-13

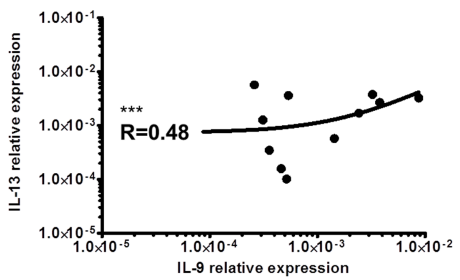

Correlation of IL-9 and IL-10
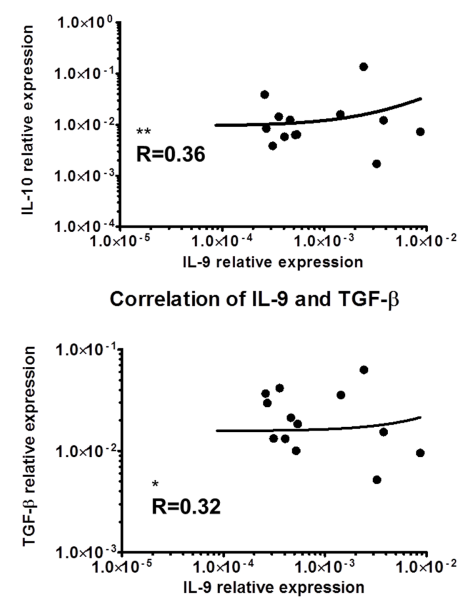

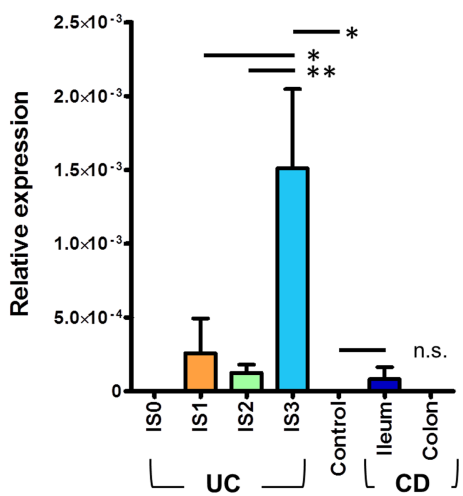

Correlation of IL-9 and IL-17A

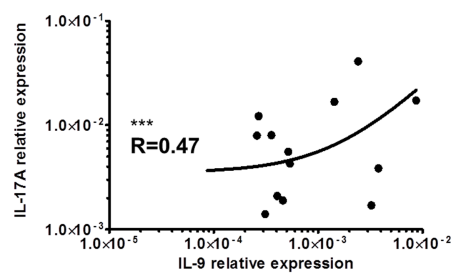

Correlation of IL-9 and IL-21
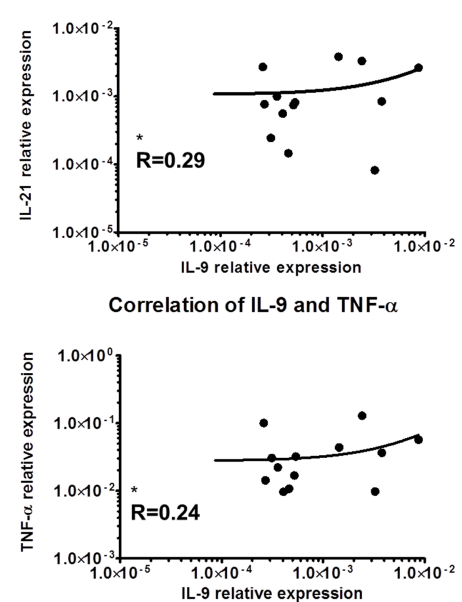

Figure 1 Interleukin (IL)-9 overexpression in mucosal biopsies from patients with UC. Patients were scored according to histopathological criteria for inflammation activity in UC ${ }^{23}$ as described in materials and methods. (A) Quantitative assessment of IL-4, IL-6, IL-9, IL-10, IL-13, IL-17A, IL-21, IFN- $\gamma$, TGF- $\beta$ and TNF- $\alpha$ mRNA expression in sigmoid colon and rectum biopsies of patients with UC with no (ISO) ( $n=7)$, mild (IS1) ( $n=11 ;$ for IL-9, $n=16)$, moderate (IS2) ( $n=9$; for IL-9, $n=27$ ) and severe (IS3) ( $n=16$; for IL-9, $n=25$ ) disease and healthy controls ( $n=10)$ shown as fold induction (left). Quantitative assessment of IL-9 mRNA expression in patients with UC and ileal $(n=9)$ and colonic biopsies ( $n=6)$ of patients with Crohn's disease with moderate and severe inflammation and healthy controls (right). CD, Crohn's disease. IS, inflammation score. (B) Correlation of IL-9 mRNA levels with levels for IL-6, IL-13, IL-17A, IL-4, IL-10, IL-21, IFN- $\gamma$, TGF- $\beta$, TNF- $\alpha$ and S100A8 mRNA in patients with UC with detectable IL-9 levels ( $n=13$ for cytokines, $n=18$ for S100A8). Data are shown as mean values \pm SEM $\left({ }^{*} p<0.05,{ }^{* *} p<0.01,{ }^{* *} p<0.001\right.$, n.s., not significant) using GraphPad Prism 5.

TGF- $\beta$ ), we isolated and stimulated blood lymphocytes from UC or healthy controls for two days with anti-CD3/anti-CD28 antibodies. Stimulated UC lymphocytes produced significantly more
IL-9 compared with unstimulated cells from the same patients (figure 5A). Cells from non-inflammatory controls that were stimulated under the same conditions produced significantly less 


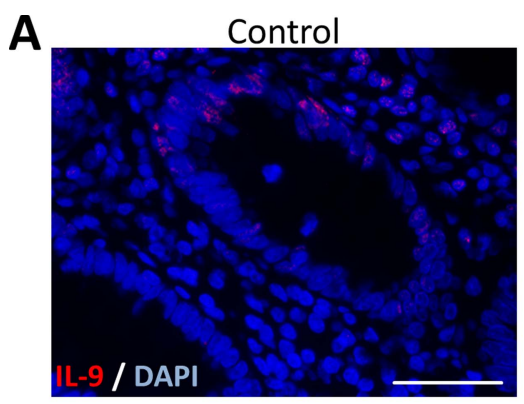

UC ISI

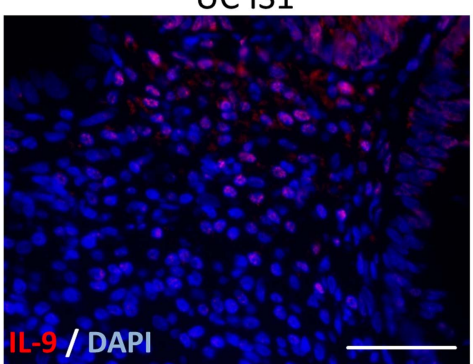

C

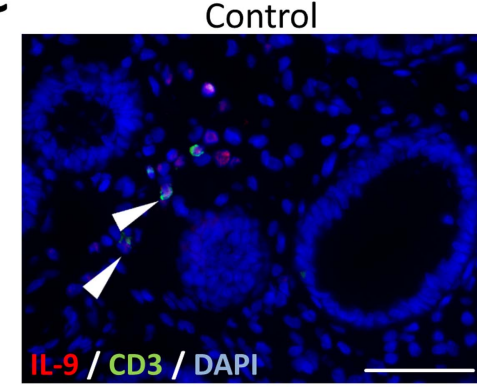

UC IS3

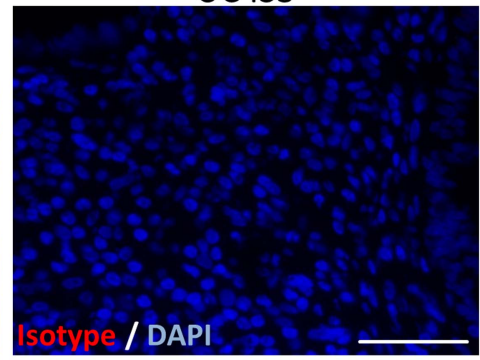

UC IS3

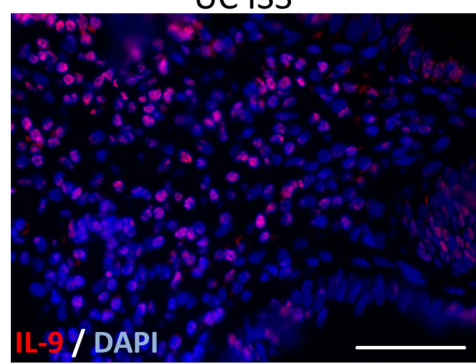

UC IS1

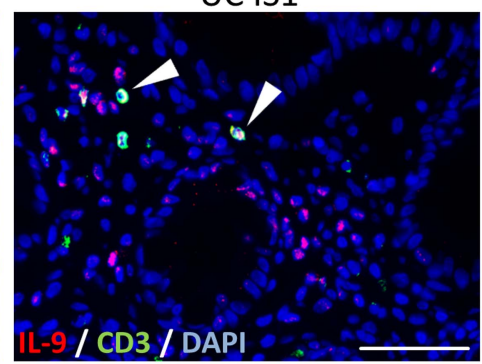

UC IS3

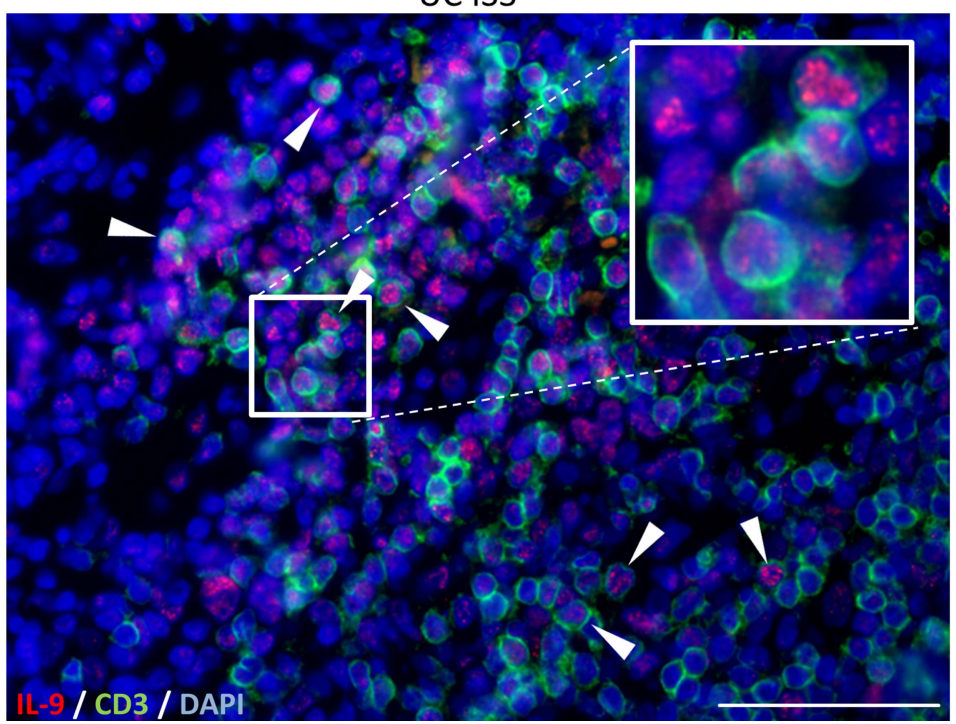

B

\section{IL-9+ cells}

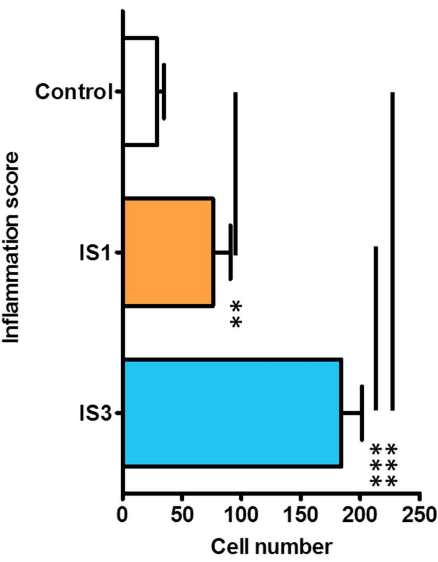

D

$\mathrm{CD}^{+} \mathrm{IL}^{-9^{+}}$cells

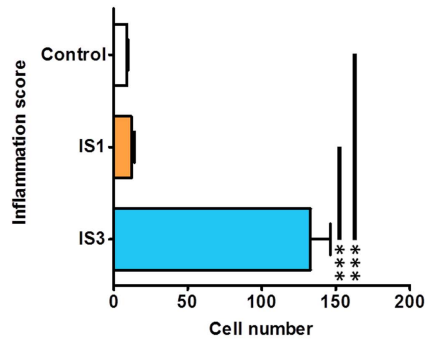

E

UC IS3

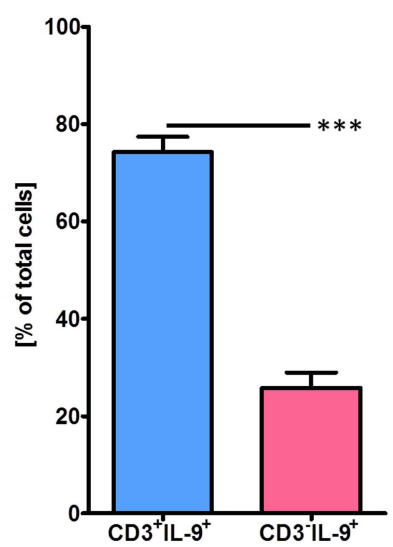

Figure 2 Interleukin (IL)-9 expression by $\mathrm{CD}^{+} \mathrm{T}$ cells is increased in the gut of patients with UC with severe inflammation. (A) Immunofluorescence staining for IL-9 of paraffin sections of human mucosal tissues from controls and patients with UC with mild (IS1) and severe (IS3) inflammation.

(B) Quantification of the IL-9-expressing cells in 7 high-power fields per patient ( $\mathrm{n}=5$ per group). (C) Immunofluorescence two-colour staining for IL-9 and CD3 of paraffin sections of mucosal tissues from controls, patients with mild (ie, IS1) and severe inflamed (ie, IS3) UC (inset: higher magnification). Representative cells coexpressing IL-9 and CD3 are marked with an arrowhead. Scale bars, all $50 \mu \mathrm{m}$. (D) Quantification of the CD3+ IL-9-expressing cells in 7 high-power fields per patient ( $\mathrm{n}=5$ per group). (E) Percentage of the $\mathrm{CD}^{+} \mathrm{IL}-9$-expressing and $\mathrm{CD} 3^{-}$IL-9-expressing cells in 7 high-power fields per patient ( $n=5$ per group). Data are shown as mean values \pm SEM $\left({ }^{* *} p<0.01,{ }^{* * *} p<0.001\right)$ using GraphPad Prism 5. IS, inflammation score.

IL-9 when compared with stimulated UC cells, whereas unstimulated control cells did not produce detectable levels of IL-9. Furthermore, we found that stimulated peripheral blood lymphocytes from patients with UC having $\mathrm{C}$ reactive protein levels $<5 \mathrm{mg} / \mathrm{L}$ produced significantly less IL-9 when compared with patients with UC with $\mathrm{C}$ reactive protein levels $>5 \mathrm{mg} / \mathrm{L}$ 
A
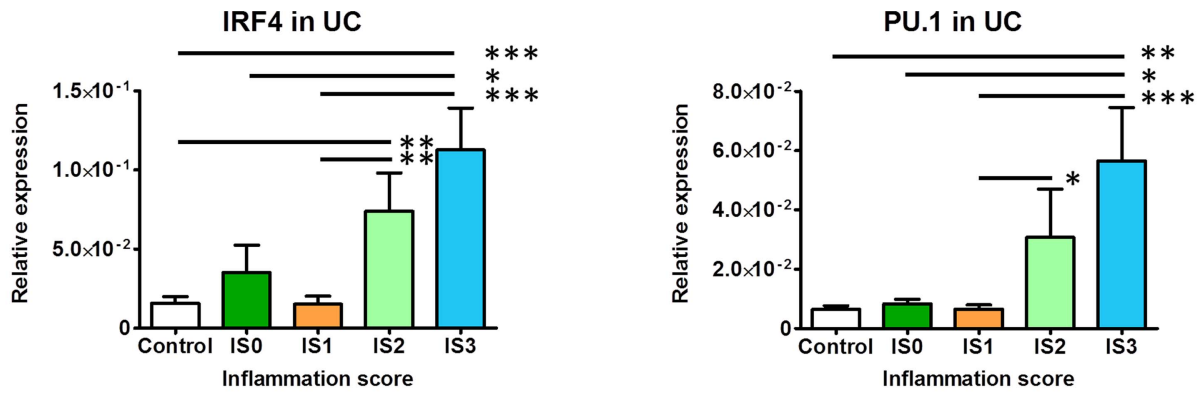

B
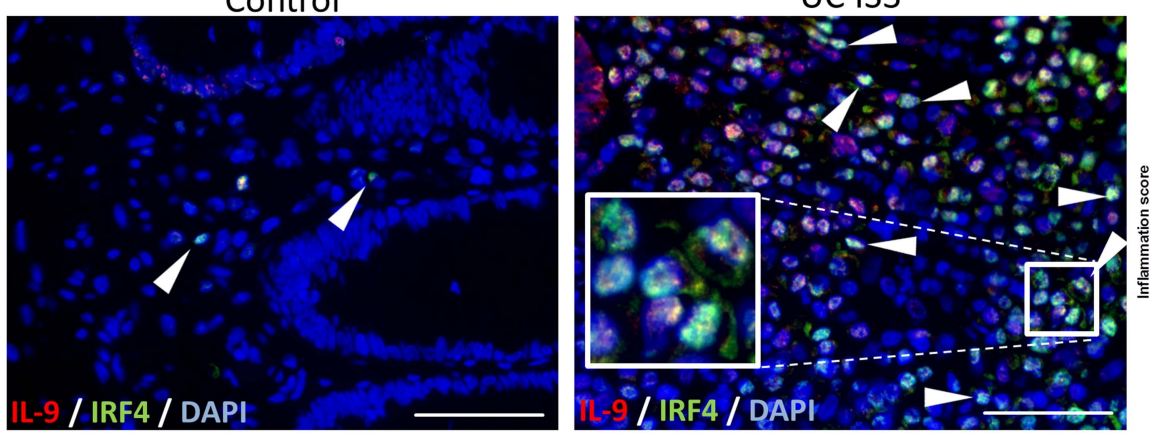

IRF4 $4^{+}$IL-9+ cells

C
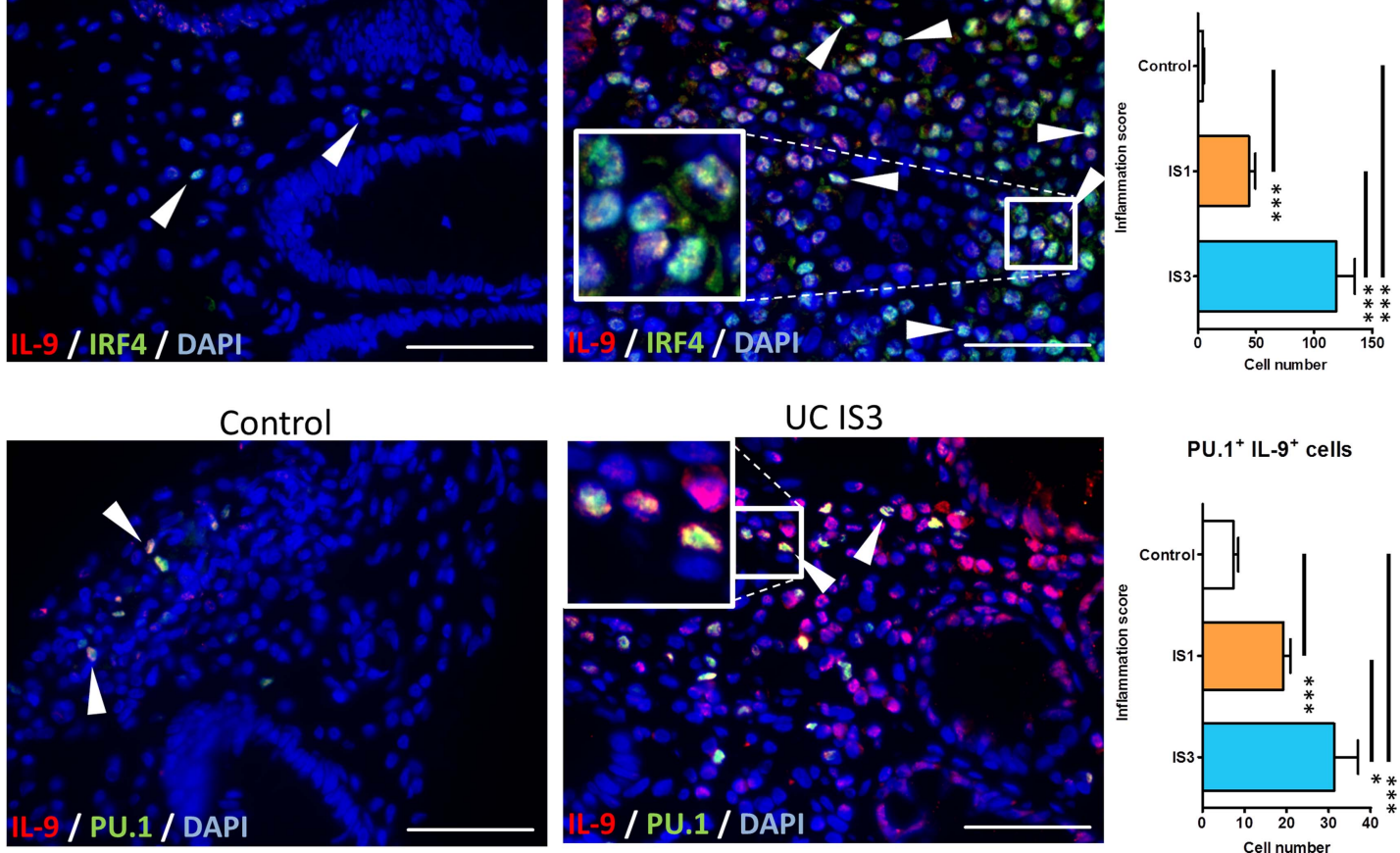

PU. $1^{+}$IL- $9^{+}$cells

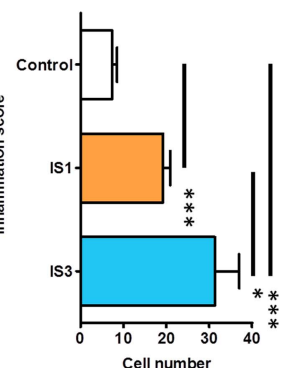

Figure 3 In UC lesions, interleukin (IL)-9 is coexpressed with the Th9 transcription factors interferon regulatory factor 4 (IRF4) and PU.1.

(A) Determination of IRF4 and PU.1 mRNA expression in the sigmoid colon and rectum biopsies of patients with UC with no (ISO) ( $n=7)$, mild (IS1) ( $n=11$ ), moderate (IS2) ( $n=9)$ and severe (IS3) ( $n=16)$ inflammation and healthy controls $(n=10)$, respectively. (B, C) Two-colour immunofluorescence staining of paraffin sections from control (left) and severe inflamed (ie, IS3) (middle) mucosal tissues for IL-9 and IRF4, and IL-9 and PU.1. Representative cells coexpressing IL-9 and IRF4 or PU.1 are indicated by arrowheads. Scale bars, all $50 \mu \mathrm{m}$ (inset: higher magnification). Quantification of the IRF4 ${ }^{+}$IL-9 ${ }^{+}$and PU. $1^{+}$IL- $9^{+}$cells in patients with UC and controls is provided (right). Cells were counted in 7 high-power fields per patient ( $\mathrm{n}=5$ per group). Data are shown as mean values \pm SEM $\left({ }^{*} p<0.05,{ }^{* *} p<0.01,{ }^{* * *} p<0.001\right)$ using GraphPad Prism 5. IS, inflammation score.

(figure 5A). IL-13 levels increased the most between healthy individuals and patients with UC, although IL-10 (5.8 times) and TGF- $\beta$ (4.6 times) levels were also considerably upregulated. Moderate correlations were observed between IL-9 and IL-13 $(\mathrm{R}=0.69 ; \mathrm{p}<0.001)$ and between IL-9 and IL-10 levels $(\mathrm{R}=0.52 ; \mathrm{p}<0.01)$, respectively (figure $5 \mathrm{~B})$. The occurrence of IL-9 producing $\mathrm{CD}^{+}$cells in the gut and the peripheral blood raised the question of whether peripheral IL-9-expressing T cells might home to the gut in UC. To address this experimentally, we analysed the expression of $\alpha 4$ and $\beta 7$ integrins in Th9 polarised blood $\mathrm{CD}^{+}$T cells. We found that $16 \%$ of the integrin $\alpha 4^{+}$and $30 \%$ of the $\beta 7^{+} \mathrm{CD}^{+}$cells expressed IL-9 (figure 5C) suggesting that circulating IL-9-expressing cells might become recruited into the inflamed gut by their surface expression of $\alpha 4$ and $\beta 7$ integrins.

\section{IL-9R overexpression is functionally relevant for antiapoptotic signals in UC}

Based on previous data indicating increased IL-9R expression on PMN from patients with asthma, ${ }^{25}$ we sought to investigate the
IL-9R expression profile on peripheral blood and gut-infiltrating PMN in patients with UC. We could demonstrate the presence of the IL-9R on cytospins by immunofluorescence (see online supplementary figure S1B). Using flow cytometry, we found that PMN from patients with UC expressed significantly more IL-9R compared with controls (figure 6A). Furthermore, CD16- eosinophils also expressed IL-9R, albeit at a lower level (figure 6A). To study functional aspects of IL-9 signalling, PMN were isolated from the peripheral blood and stimulated with various doses of recombinant IL-9. We observed a dose-dependent IL-8 production (figure $6 \mathrm{~B}$ ). This effect could be inhibited by preblocking IL-9R signalling in PMN from patients with UC (figure 6B). Granulocyte macrophage colony stimulating factor (GM-CSF)-stimulated PMN from patients with UC that served as stimulation controls produced significantly more IL-8 compared with control PMN (figures 6B). Traditionally, PMN were considered to be short-lived terminally differentiated cells whose life span can be substantially increased by proinflammatory stimuli. ${ }^{26}$ To investigate the ability of IL-9 to modulate PMN survival, we incubated cells with different doses of IL-9. 
A UC blood cells non-polarized

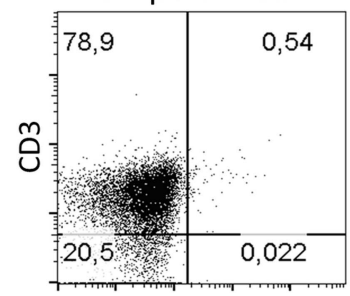

IL-9

B
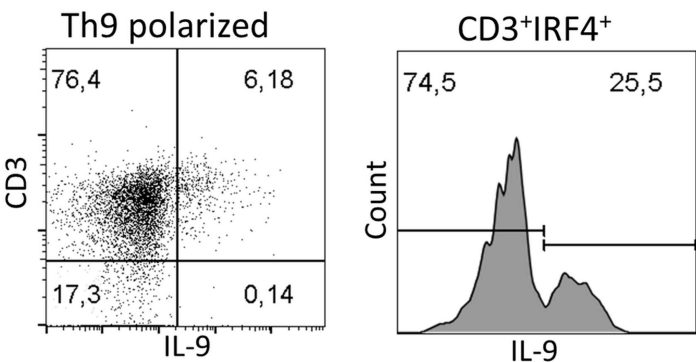

IL-9
$\mathrm{CD}^{+}$IRF4 ${ }^{+}$

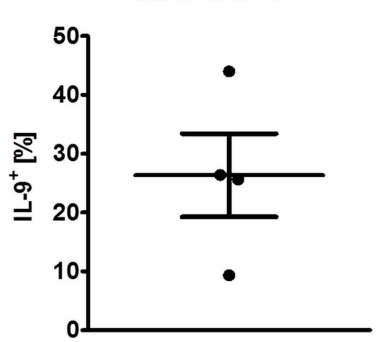

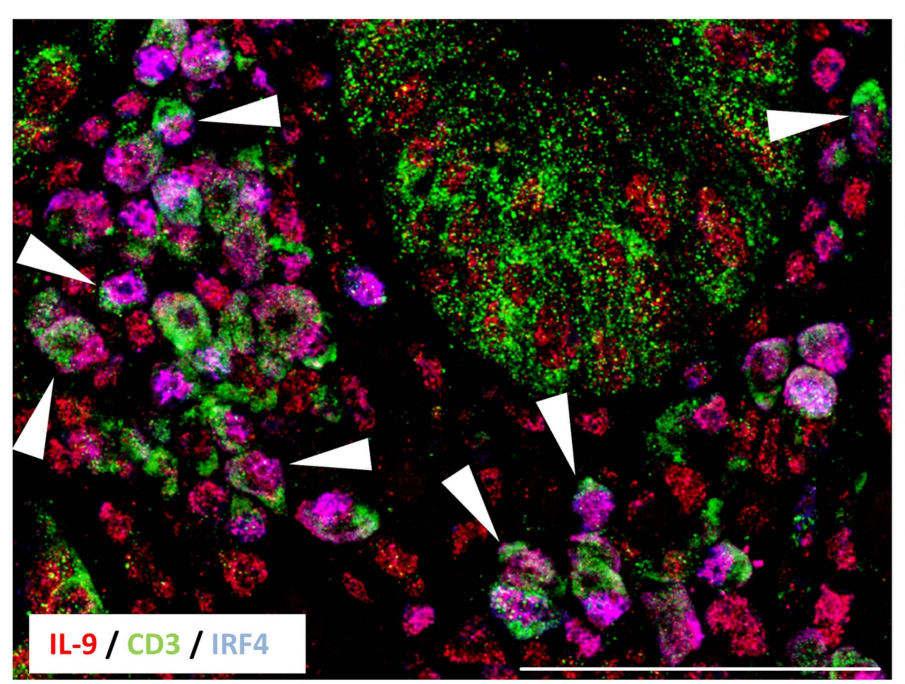

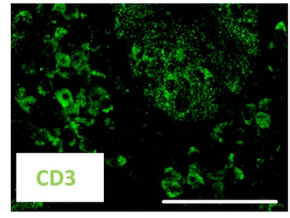

\section{$\mathrm{CD}^{+}$cells}

80
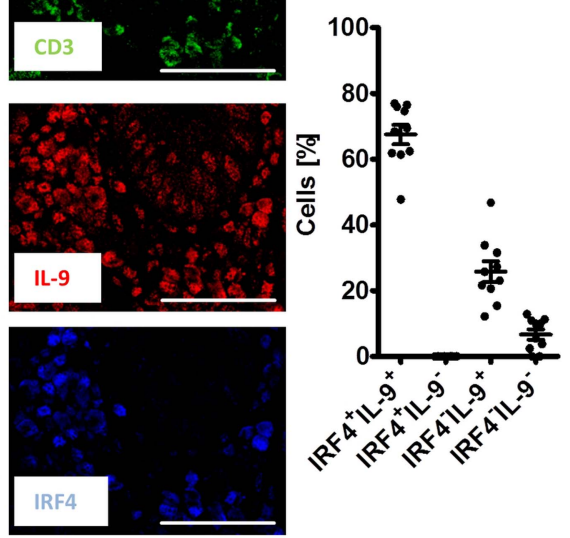

\section{C}
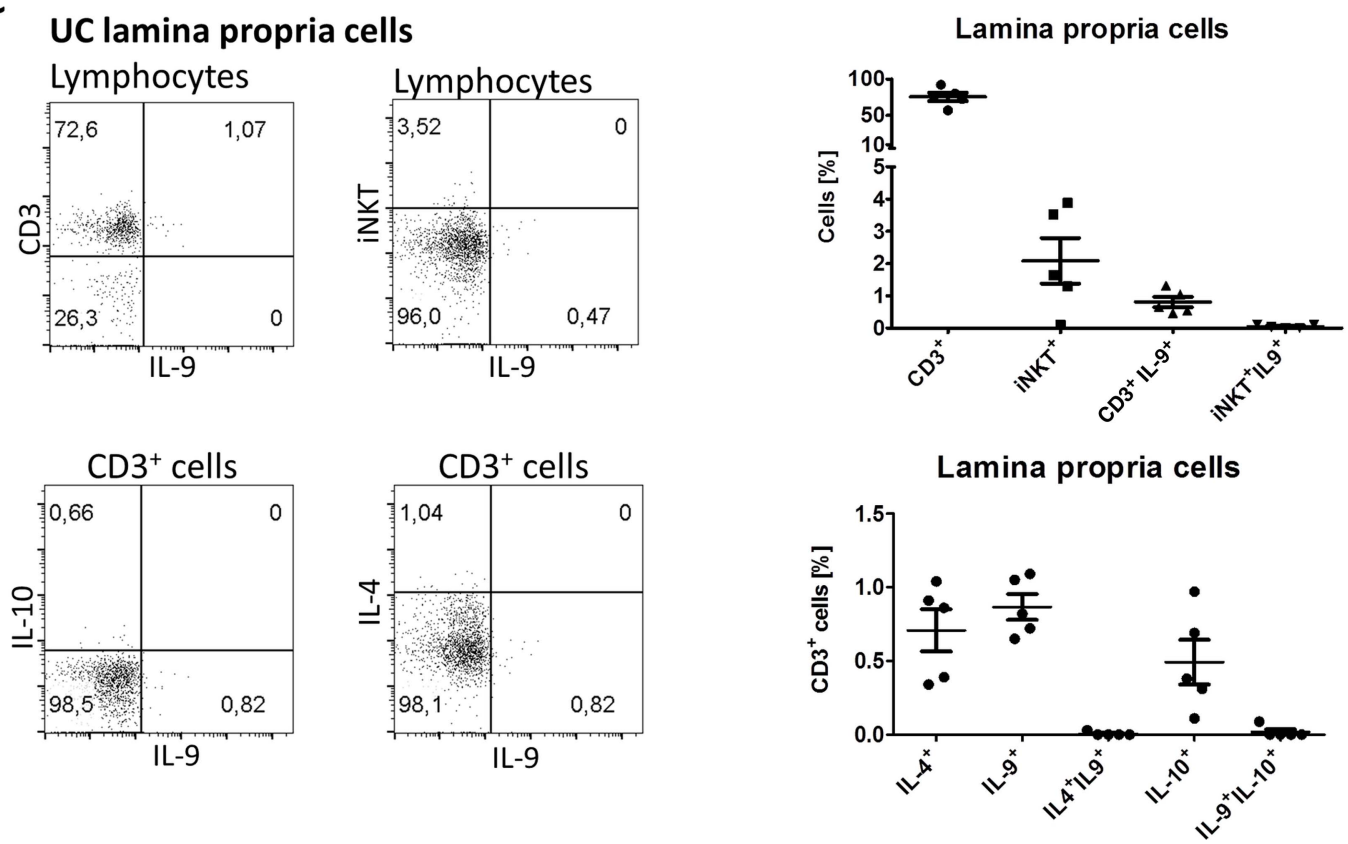

Figure 4 In patients with UC, IL-9 is induced by interferon regulatory factor 4 (IRF4) but is not coexpressed with IL-4 or IL-10. (A) Dot plots of representative $\mathrm{CD}^{+}$IL-9-expressing blood lymphocytes from patients with UC under non-polarised and Th9 polarised conditions (left). Histogram indicates the percentage of IL-9-expressing cells among gated $\mathrm{CD}^{+}{ }^{+} \mathrm{IRF}^{+}$cells in Th9 polarised cells. Quantification of pooled data from four patients is shown for $\mathrm{CD}^{+}{ }^{+}$IRF4 ${ }^{+}$gated cells. (B) Representative confocal microscopy image of human mucosal tissue from patients with UC with severe inflammation (ie, IS3). Cells coexpressing IL-9, CD3 and IRF4 are marked with an arrowhead. Scale bars, all $50 \mu \mathrm{m}$. Quantification of data from 7 high-power fields indicating the percentage of IRF4 ${ }^{+}$IL-9 $9^{+}$, IRF4 ${ }^{+}$IL-9- $9^{-}$IRF4 $4^{-}$IL-9 $9^{+}$and IRF4 ${ }^{-}$IL-9- ${ }^{-}$among CD3 ${ }^{+}$cells is provided (right). (C) Representative flow cytometry data of IL-9 production by CD3 and $V \alpha 24-J_{\alpha} 18$ (the invariable NKT cell marker) populations in the lamina propria (top). IL-10-production, IL-9-production and IL-4-production in distinct populations of $\mathrm{CD}^{+}$cells in the lamina propria from inflamed UC lesions (bottom). Quantification of data pooled from five patients with inflamed UC lesions (right). IS, inflammation score. 
A

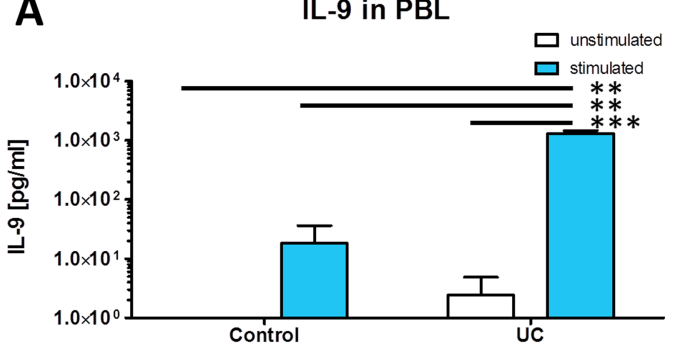

B

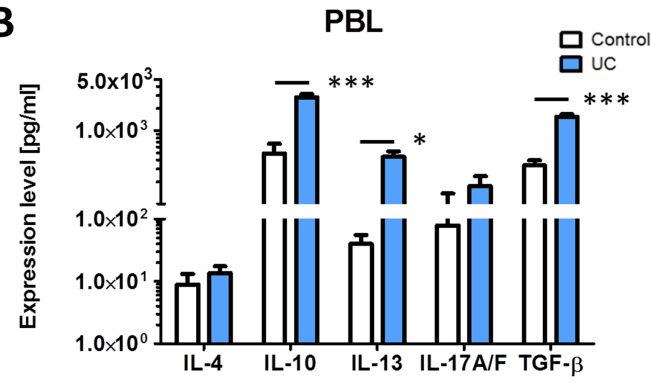

Correlation of IL-9 and IL-10

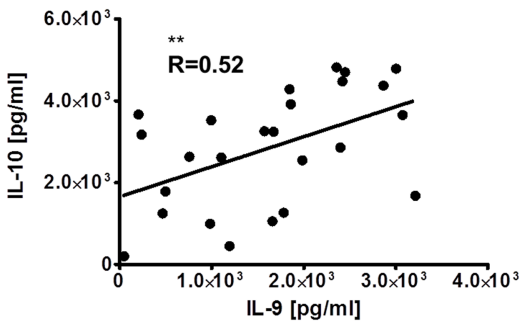

Correlation of IL-9 and IL-17A/F

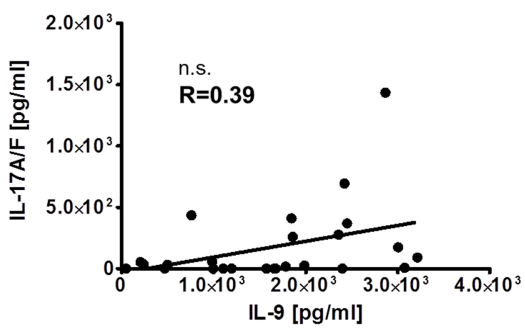

C Th9 polarized $\mathrm{CD}^{+}$blood cells
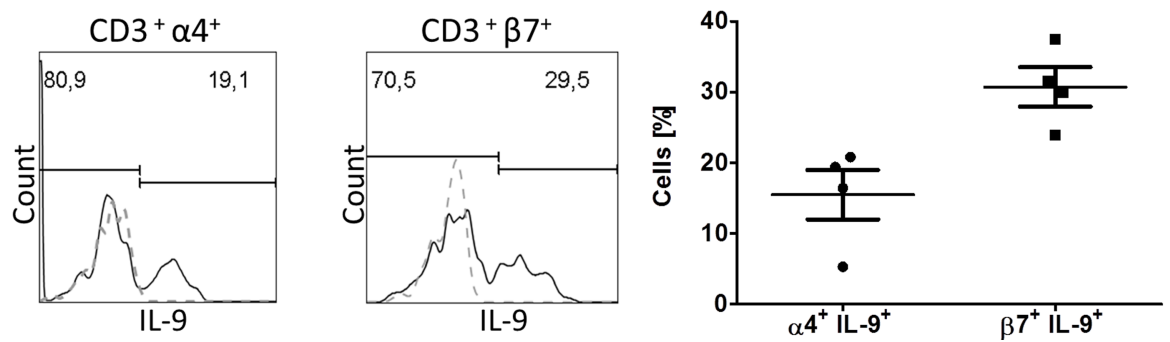

Figure 5 Production of cytokines by cultured peripheral blood lymphocytes and expression of gut homing markers in Th9 polarised cells.

(A) Enzyme-linked immunosorbent assay detection of IL-9 levels produced by unstimulated and anti-CD3/anti-CD28-stimulated peripheral blood lymphocytes from patients with UC $(n=33)$ and non-inflammatory controls $(n=7)$ (left). Patients with UC were grouped according to their $C$ reactive protein value into $C$ reactive protein $<5 \mathrm{mg} / \mathrm{L}(\mathrm{n}=16)$ and $\mathrm{C}$ reactive protein $>5 \mathrm{mg} / \mathrm{L}(\mathrm{n}=17)$. (B) Enzyme-linked immunosorbent assay levels for IL-4, IL-10, IL-13, IL-17A/F and TGF- $\beta$ in stimulated blood cells from patients with UC $(n=25)$ and controls $(n=7)$ are shown (top left). Correlations of IL-9 levels with levels for IL-4, IL-10, IL-13, IL-17A/F and TGF- $\beta$ in patients with UC $(n=25)$ are provided. Data are shown as mean values \pm SEM $\left({ }^{*} p<0.05,{ }^{* *} p<0.01\right.$,

${ }^{* * *} \mathrm{p}<0.001$, n.S., not significant) using GraphPad Prism 5. (C) Representative flow cytometry data of the expression of IL-9 in CD $3^{+} \alpha 4$ integrin ${ }^{+}$and $\mathrm{CD}^{+} \beta 7$ integrin ${ }^{+}$cells, respectively, in whole blood IL-9-expressing lymphocytes (Isotype — grey, dashed line; stained sample — black line) (left). Quantification indicates the percentages of IL-9-expressing cells in the gated $\alpha 4$ integrin ${ }^{+}$and $\beta 7$ integrin ${ }^{+}$cells of four patients with UC (right). 
A
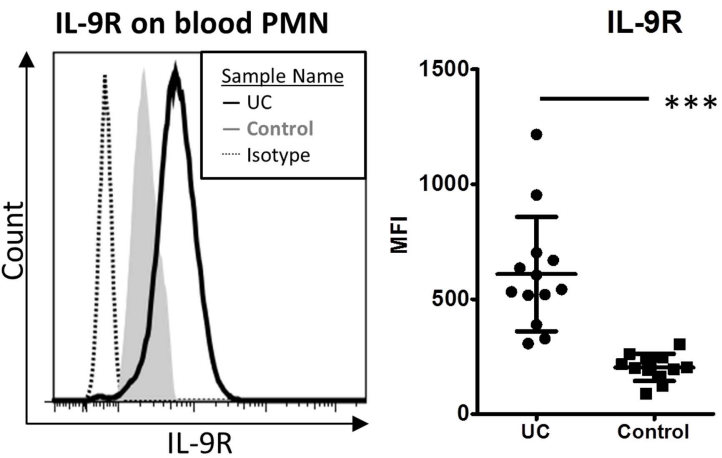

B PMN
UC blood PMN
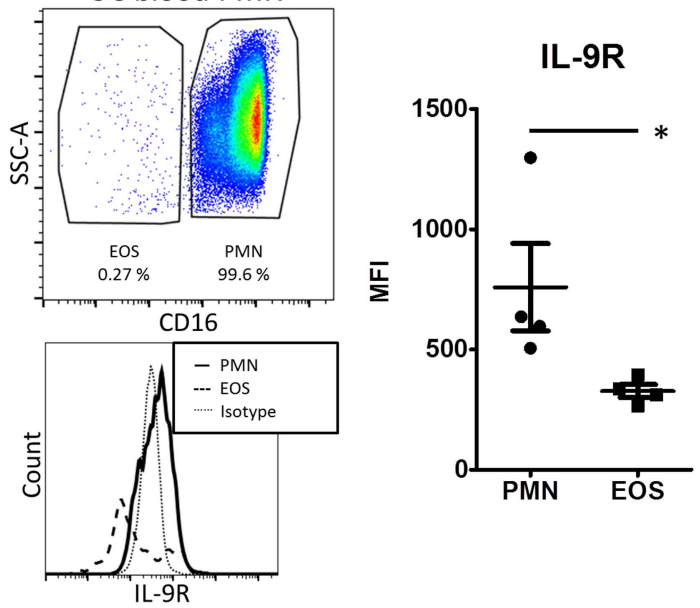

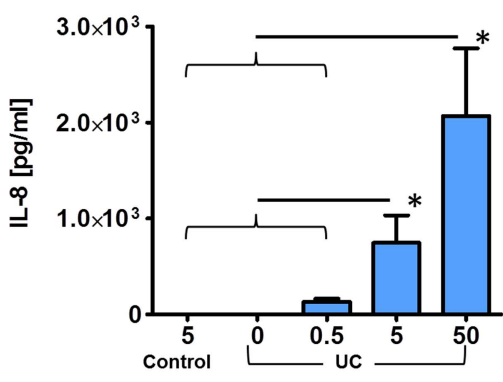

IL-9 concentration [ng/ml]

C

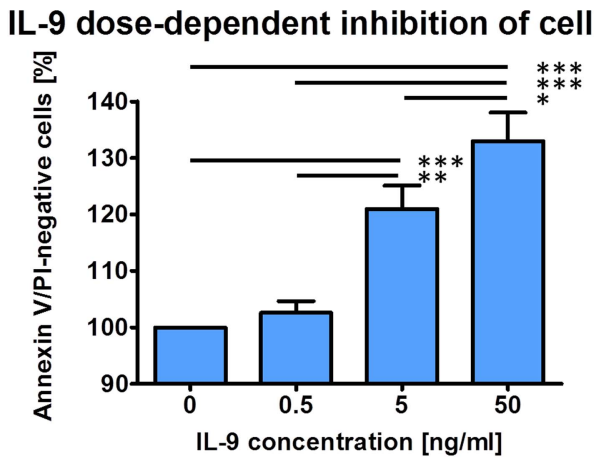

D

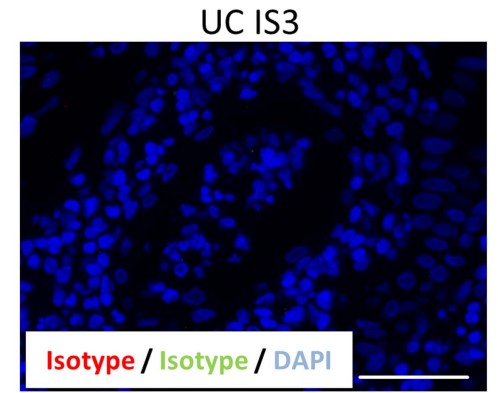

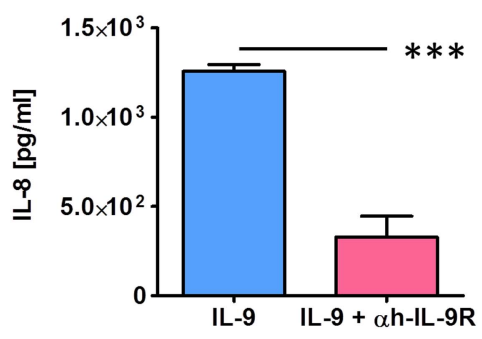

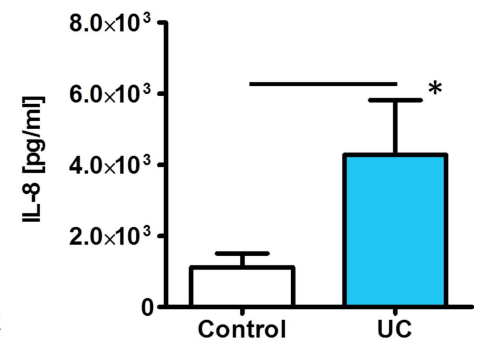

IL-8 dependent inhibition of cell death

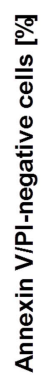

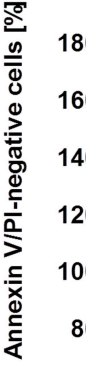

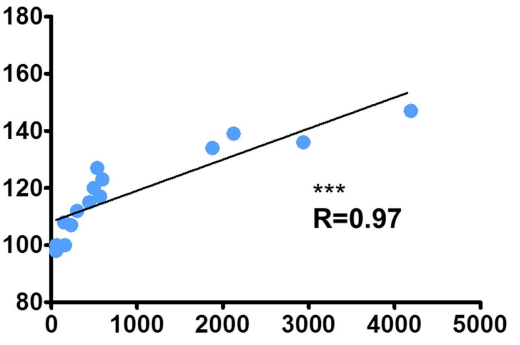

IL-8 concentration $[\mathrm{pg} / \mathrm{ml}]$

UC IS3

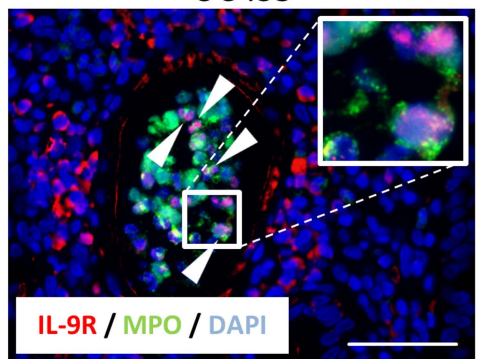

Figure 6 IL-9-induced IL-8 production and delayed apoptosis of IL-9R-overexpressing polymorphonuclear leucocytes (PMN) in patients with UC. (A) Representative flow cytometry histogram of IL-9R expression on blood granulocytes from patients with UC and healthy controls is shown (left). Quantification of the IL-9R staining in UC $(n=13)$ and controls $(n=12)$ (second from left). Representative dot plot of gated granulocytes based on their CD16 expression and side scatter (SSC) properties (second from right, top). IL-9R expression in PMN and in eosinophils is shown in a representative flow cytometry histogram (second from right, bottom). Quantification of the IL-9R expression levels in PMN and eosinophils ( $n=4)($ right). EOS, Eosinophils. (B) IL-9-induced dose-dependent production of IL-8 in supernatants of stimulated PMN from patients with UC and controls ( $n=5$ per group) (left). IL-8 production in PMN preparations from UC by stimulation with $50 \mathrm{ng} / \mathrm{mL} \mathrm{IL-9}$ and the use of an anti-hIL-9R blocking antibody ( $\mathrm{n}=4$ ) (middle). IL-8 production in GM-CSF-stimulated PMN from controls $(n=9)$ and patients with UC ( $n=11)$ (right). (C) Quantification of apoptosis rates in PMN stimulated with different doses of IL-9 $(0,0.5,5,50 \mathrm{ng} / \mathrm{ml})$ (left); correlation between IL-9-induced IL-8 levels and IL-9-induced apoptosis resistance after $18 \mathrm{~h}$ (right) $(n=5)$. Data are shown as mean values \pm SEM $\left({ }^{*} p<0.05,{ }^{* *} p<0.01,{ }^{* *} p<0.001\right)$ using GraphPad Prism 5. (D) Two-colour immunofluorescence staining of paraffin sections of human mucosal tissues showing a crypt abscess with IL-9R and myeloperoxidase double positive PMN (inset: higher magnification). Representative cells coexpressing IL-9R and myeloperoxidase are marked with an arrowhead. Scale bars, all $50 \mu \mathrm{m}$. 
After 18 h, PMN were stained with Annexin V and Propidium iodide and apoptosis rates were determined (see online supplementary figure S1C). IL-9-induced signals rendered PMN resistant to apoptosis in a dose-dependent manner (figure 6C) which correlated well with levels of IL-8 production by these cells (figure 6C). Importantly, crypt abscesses from patients with severe inflammation were dominated by $\mathrm{IL}-9 \mathrm{R}^{+}$and myeloperoxidase $^{+}$PMN, suggesting a functional role for IL-9 signalling in PMN in UC (figure 6D).

\section{IL-9 induces STAT5 phosphorylation in primary gut epithelial cells}

Extensive analysis of gut specimens revealed that cells within the lamina propria and the epithelial layer expressed the IL-9R (figure 7A). More specifically, epithelial cells populating crypts above the ' +4 ' position expressed IL-9R in patients with mild (ie, IS1) and severe (ie, IS3) inflammation as well as controls (figure 7A) suggesting that IL-9R expression is not Paneth cell or stem cell related. Quantification of the IL-9R ${ }^{+}$cells in the lamina propria together with epithelium indicated significantly increased numbers in severe UC (ie, IS3) compared with mild inflammation (ie, IS1) and with controls, respectively, as well as between mild inflammation and controls (figure 7A). To further investigate the IL-9R-expressing cells in situ, epithelial cells from resected tissues were stained with antibodies to epithelial cell adhesion molecule (EpCAM), CD3 and IL-9R. EpCAM ${ }^{+}$ epithelial cells showed consistent IL-9R expression levels (figure 7B upper histogram) whereas intraepithelial $\mathrm{CD}^{+}$lymphocytes (middle histogram) and $\mathrm{CD}^{-}{ }^{-}$EpCAM $^{-}$-cells (lower histogram) showed marginal IL-9R expression. Moreover, $\mathrm{EpCAM}^{+}$epithelial cells of patients with UC with severe inflammation (ie, IS3) expressed IL-9R to a higher extent than controls (figure 7B). To gain more insights into the mechanistic function of IL-9 on the gut epithelium, we stimulated freshly isolated epithelial cells with IL-9. Control preparations were either incubated in medium alone or preincubated for $60 \mathrm{~min}$ with an anti-hIL-9R blocking antibody before IL-9 was added. After 60 min of IL-9 stimulation we observed significantly more pSTAT5 in cells receiving IL-9 compared with cells incubated in medium only whereas preblocked preparations had intermediate levels of STAT5 activation (figure 7C).

\section{Blocking IL-9R accelerates wound healing}

To functionally address the role of IL-9 in the gut physiology, we used Caco-2 monolayers as a model of the gut epithelium. First we demonstrated that these cells express the IL-9R (figure 8A). To exclude a possible proapoptotic effect of IL-9, we stained for active caspases using staurosporin-induced $(2 \mu \mathrm{M}$ for $12 \mathrm{~h}$ ) apoptosis as a control (figure $8 \mathrm{~B}$ ). Cells were then seeded in culture-inserts and after reaching confluence, an artificial gap was produced by removing the insert from the culture vessel. Cells were then incubated for $60 \mathrm{~min}$ either with an anti-hIL-9R blocking antibody or with medium alone and $100 \mathrm{ng} / \mathrm{mL}$ IL-9 was added for additional $18 \mathrm{~h}$. Control preparations received only medium. Interestingly, IL-9 delayed Caco-2 cells' growth in a significant manner whereas IL-9R blockade limited the potential of IL-9 to interfere with cell growth (figure $8 \mathrm{C}$ ) providing evidence for a potential pathogenic role of IL-9 in the context of mucosal healing in UC.

\section{DISCUSSION}

The better understanding of molecular mechanisms driving chronic gut inflammation has led over the past two decades to novel therapeutic strategies with great impact for the current management of IBD. ${ }^{27-29}$ However, despite spectacular successes mainly attributable to the anti-TNF therapy, ${ }^{27} 29$ not all patients respond to the newer drugs and about a third of the responders relapse within a short time. ${ }^{27}$ Further studies are therefore needed to identify novel therapeutic molecules in IBD. ${ }^{27}{ }^{30}$ In the present study, we set out to investigate the role of IL-9 in the pathogenesis of UC. Our results demonstrated that IL-9 is involved in promoting inflammation in UC by acting on IL-9R overexpressing gut epithelial cells and PMN. Furthermore, IL-9 should be considered as a potential novel marker for monitoring the severity of disease as IL-9 levels correlated with the severity of disease and with levels of the systemic proinflammatory S100A8 protein in UC. Nevertheless, since current anticytokine strategies mainly focus on targeting the Th1 or Th2 pathways, interfering with IL-9 signalling might emerge as starting point for specific therapeutic approaches.

Since its conception, the Th1/Th2 paradigm has dominated the immunological thinking for almost two decades. ${ }^{31}$ However, due to recent advances in the field of transcriptional regulation of immune responses, many of the functions attributed to either the Th1 or the Th2 populations are increasingly becoming associated with the newly discovered $\mathrm{Th}^{7} 7^{7}$ and/or $\mathrm{Th}^{12}{ }^{15}$ cells. Whereas the role of IL-17 is relatively well characterised, ${ }^{2} 7$ the role of IL-9 in UC has not yet been investigated. In the present study, we therefore addressed the role of IL-9 and the key Th9 transcription factors IRF4 ${ }^{19}$ and PU. $1^{20}$ in UC disease pathogenesis.

Interestingly, we found significantly increased expression of IL-9 mRNA levels in patients with severe inflammation compared with controls. Furthermore, the relative expression of IL-9 best correlated with that of S100A8, high levels of which were previously reported in active UC. ${ }^{32}$ Among investigated cytokines, IL-9 mRNA levels best correlated with those of IL-6 and IL-17A, whose altered expression was previously linked to UC. ${ }^{21} 22$

To extend our findings to the protein level in situ, we stained paraffin gut biopsies and resected tissues from patients with UC with mild and severe disease as well as controls. In patients with UC with severe disease IL-9 expression was significantly increased compared with mild disease UC and controls, respectively. In addition, IL-9 expression was largely restricted to lamina propria cells and two-colour immunofluorescence stainings indicated that $\mathrm{CD}^{+} \mathrm{T}$ cells accounted for more than $75 \%$ of the IL-9-expressing cells in IS3 lesions. To clarify the nature of the CD3 ${ }^{-}$IL-9-expressing cells, we stained for IL-9 and myeloperoxidase as a marker of PMN since these cells have been reported to be able to produce IL- $9^{33}$ and often dominate the picture in acute UC lesions. ${ }^{23}$ Interestingly, PMN did produce IL-9 in UC lesions (see online supplementary figure S1). In mice, IL-9 production has also been associated with type 2 innate lymphoid cells. ${ }^{14} 15$ Since no antibodies are currently available to stain these cells in sections of human bowel we cannot completely exclude the fact that innate lymphoid cells produce IL-9 in UC. Nevertheless, our data clearly demonstrate that $\mathrm{CD}^{+}$cells are the main producers of IL-9 in UC.

To gain more functional insights into IL-9 actions in UC, we performed two-colour immunofluorescence stainings for IL-9 and IRF4 or PU.1, the two key transcription factors of Th9 cells. ${ }^{19} 20$ We found significantly more IL- $9^{+} \mathrm{IRF}^{+}$and to a lesser extent IL- $9^{+}$PU. $1^{+}$cells in severe disease compared with mild disease and controls, respectively. Furthermore, the co-localisation of IL-9 and IRF4 in individual cells suggests a multifaceted role of IRF4 in the pathogenesis of IBD. Although previous data defined a critical role for IRF4 in the IL-6- and IL-17-dependent gut pathology, ${ }^{21} 22$ our present results indicate 
A

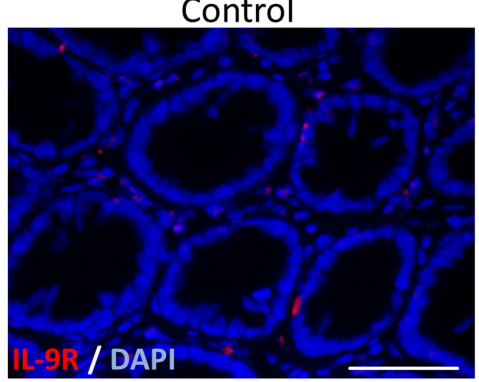

UCIS1

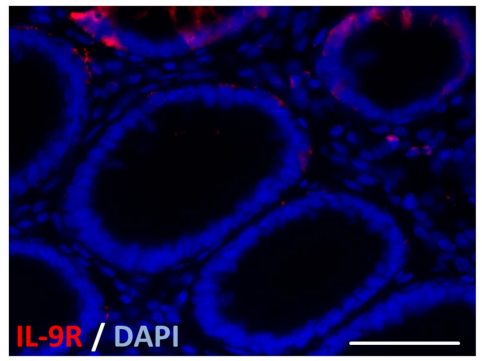

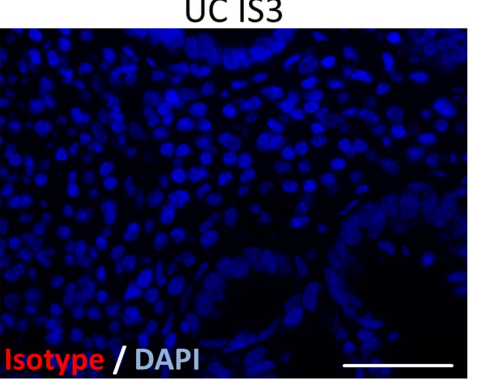

UCIS3

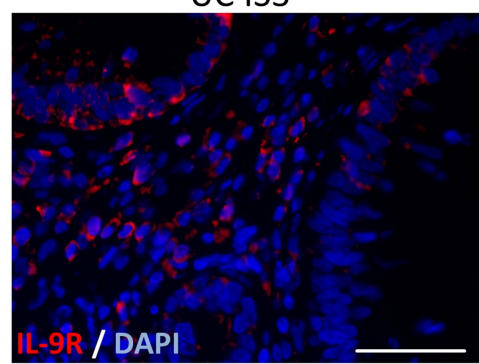

IL-9R ${ }^{+}$cells

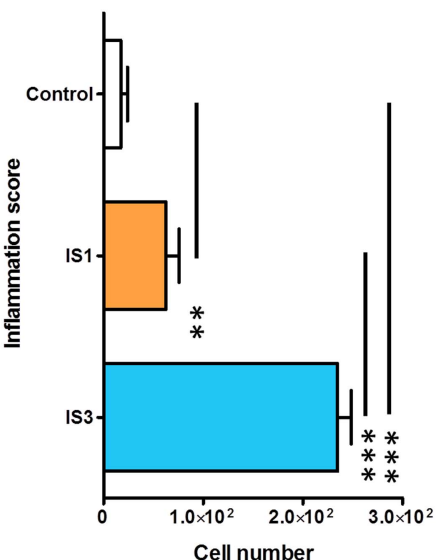

Cell number

B
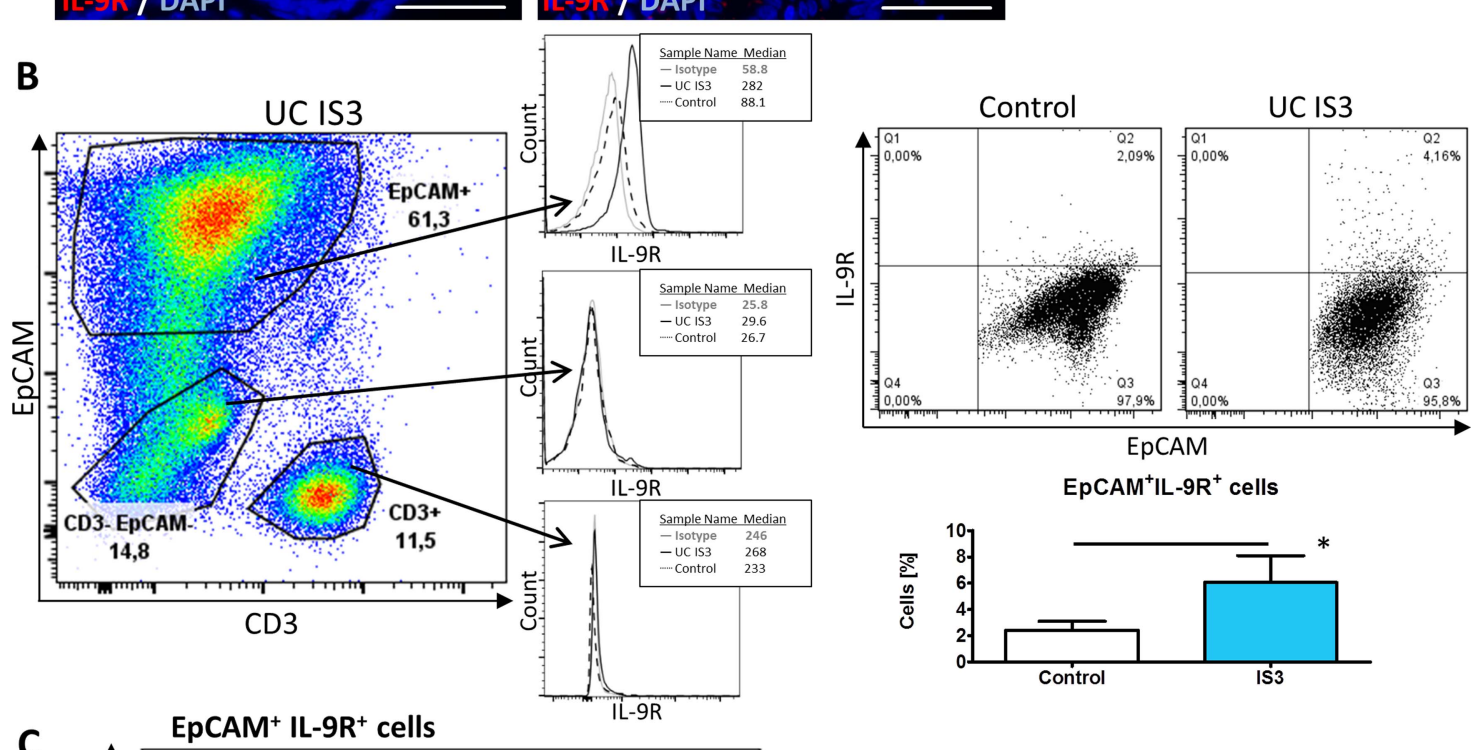

C
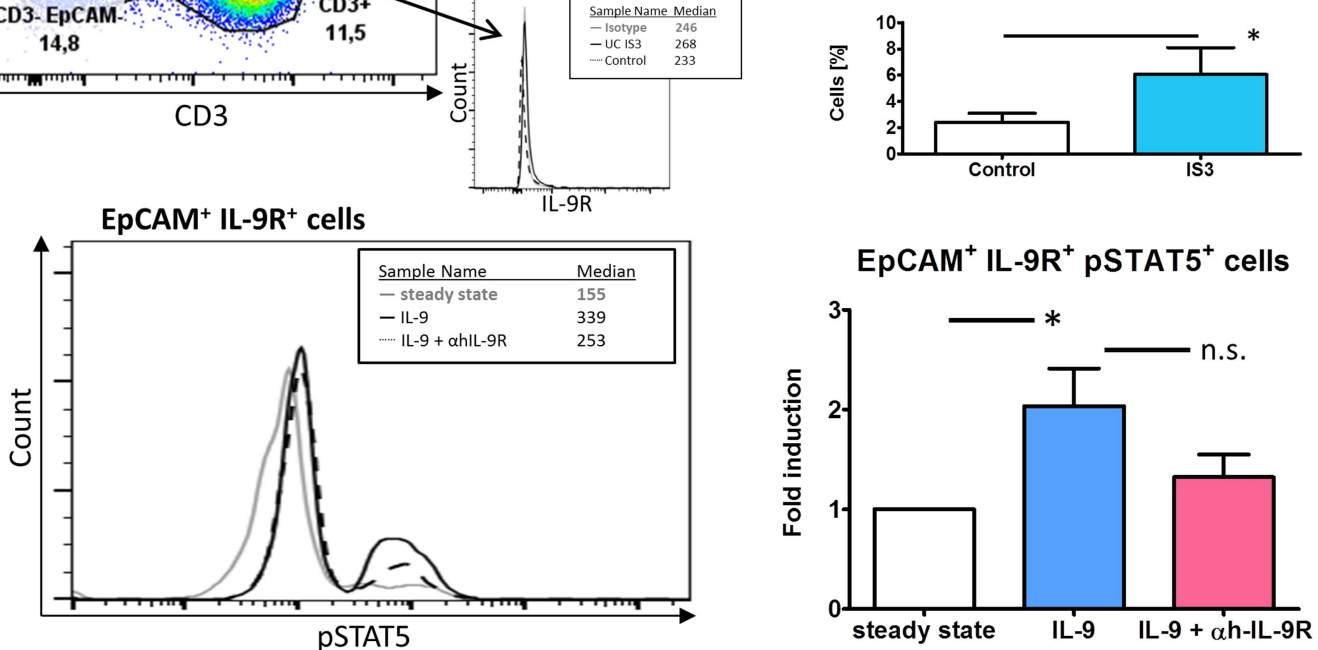

EpCAM $^{+}$IL-9R $^{+}$pSTAT5 ${ }^{+}$cells

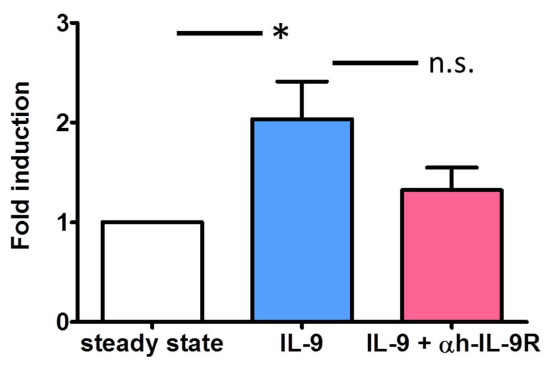

Figure 7 In gut epithelial cells IL-9 activates STAT5. (A) IL-9R immunofluorescence of paraffin sections of human mucosal tissues from control and patients with UC with mild (ie, IS1) and severe (ie, IS3) inflammation (left, middle). Scale bars, all $50 \mu \mathrm{m}$. Quantification of the IL-9R ${ }^{+}$cells in 7 high-power fields per patient ( $n=5$ per group) (right). (B) Epithelial cells isolated from resected tissue were analysed by flow cytometry. Cells were stained with EpCAM to gate for epithelial cells $\left(\mathrm{EpCAM}^{+}\right)$and with $\mathrm{CD} 3$ to gate for intraepithelial lymphocytes $\left(\mathrm{CD}^{+}\right)$and the double negative population (CD3- EpCAM $^{-}$) (left). Representative flow cytometry data for IL-9R expression in one patient with UC IS3 and control in those gated cell populations is shown (middle). Representative panel of $\mathrm{EpCAM}^{+}$cells from one patient with severely inflamed UC (ie, IS3) and one control are shown (right, top). Quantification of EpCAM ${ }^{+}$IL-9R $^{+}$cells (\%) (right, bottom). Resected tissues from 14 patients (10 controls, 4 patients with UC IS3) were analysed by flow cytometry. (C) Epithelial cells were stimulated with $100 \mathrm{ng} / \mathrm{mL}$ IL-9 with or without $1 \mu \mathrm{g} / \mathrm{ml}$ anti-hlL-9R pretreatment and investigated for PSTAT5 expression. Representative flow cytometry panel of $\mathrm{EpCAM}^{+} \mathrm{IL}-9 \mathrm{R}^{+}$cells from one control is shown (left). Quantification of $\mathrm{EpCAM}^{+} \mathrm{IL}^{-9 R^{+}}$pSTAT5 ${ }^{+}$cells of stimulated controls $(n=4)$ are shown as fold induction as compared with steady state (right). Data are shown as mean values $\pm \operatorname{SEM}\left({ }^{*} p<0.05,{ }^{* *} p<0.01,{ }^{* *} p<0.001\right.$, n.s., not significant) using GraphPad Prism 5. IS, inflammation score. 
A

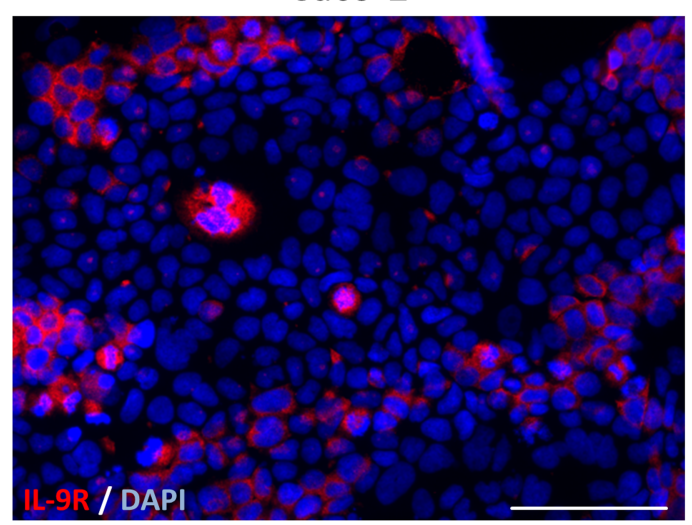

Caco-2

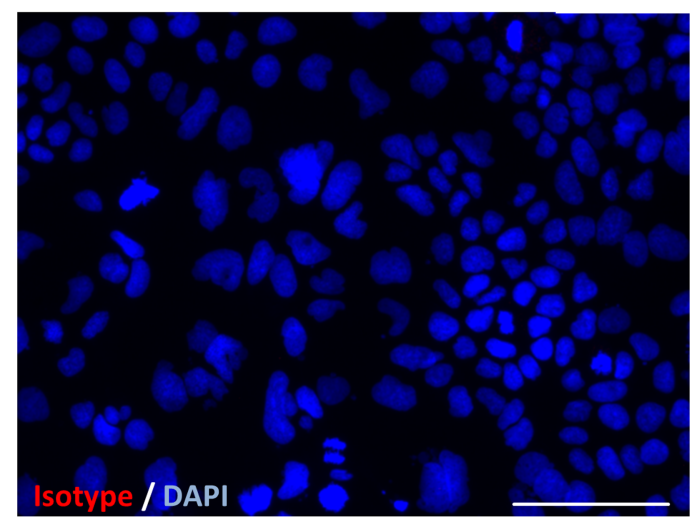

$100 \mathrm{ng} / \mathrm{ml} \mathrm{IL-9}$

B
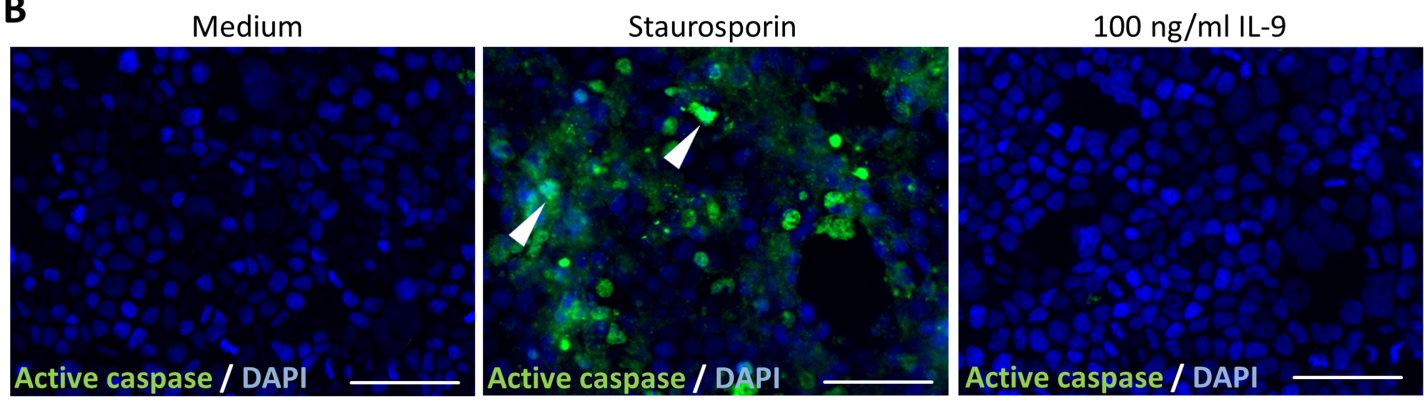

C

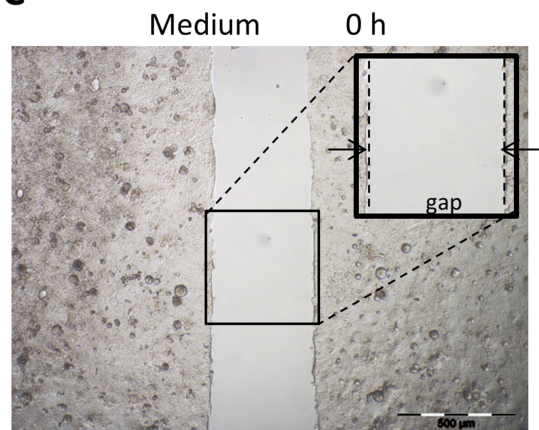

IL-9

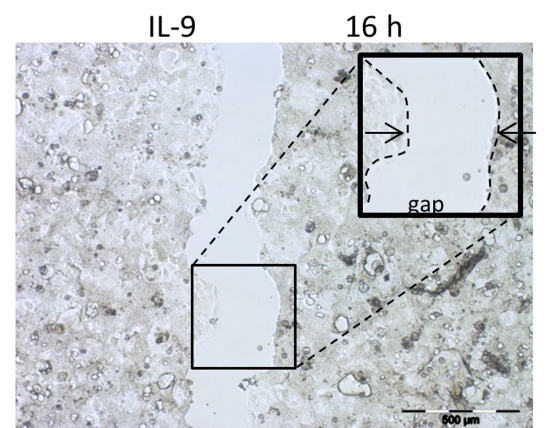

Medium

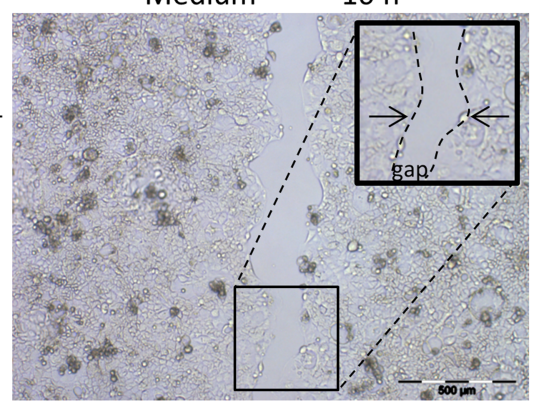

IL-9 + $\alpha h-I L-9 R$

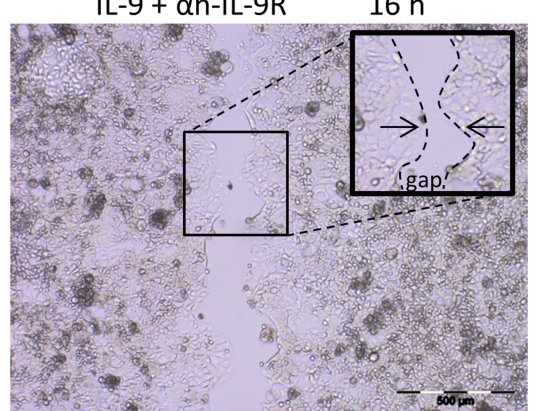

Wound healing assay

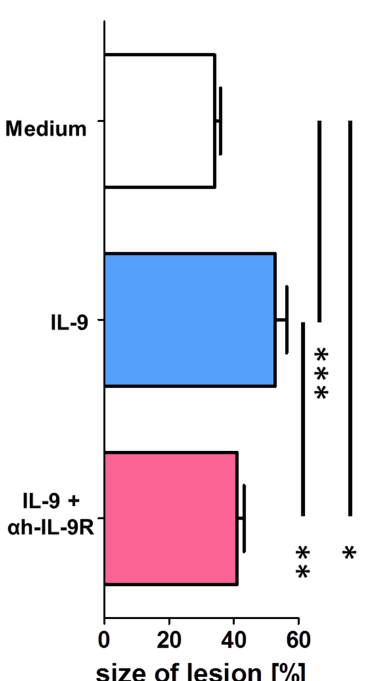

size of lesion [\%]

Figure 8 Interleukin (IL)-9-induced delay in wound healing assayed by intestinal epithelial Caco-2 cell scratch assays. (A) IL-9R immunofluorescence staining of Caco-2 cells grown on chamber slides. Scale bars, all $50 \mu \mathrm{m}$. (B) Active caspase staining of Caco-2 cells $48 \mathrm{~h}$ after addition of $100 \mathrm{ng} / \mathrm{mL}$ IL-9. Staurosporin ( $2 \mu \mathrm{M}$ for $12 \mathrm{~h}$ ) served as a positive control. Representative caspase-positive cells are marked with an arrowhead. A second independent experiment showed similar results. (C) $100 \mathrm{ng} / \mathrm{mL}$ IL-9, with or without $1 \mu \mathrm{g} / \mathrm{mL}$ anti-hIL-9R pretreatment, was added to Caco-2 cells grown to confluence on culture-inserts and cells were investigated in duplicates in three independent wound healing experiments. Representative pictures of one experiment are shown (left, middle) and quantification of lesion size (\%) as indicated (right). Data are shown as mean values \pm SEM $\left({ }^{*} p<0.05,{ }^{* *} p<0.01,{ }^{* * *} p<0.001\right)$ using GraphPad Prism 5.

that IRF4 might exert alternative and probably synergistic actions by modulating the IL-9-driven inflammation in the gut. To more precisely address the functional role of IRF4 in the generation of IL-9 in the context of UC, we investigated the ability of IL-4 and
TGF- $\beta$ to induce IL-9 expression in Th9 polarised blood lymphocytes. Consistent with previously reported rates of IL-9 expression in polarised human Th9 cells ${ }^{34-36}$ we detected about $6 \%$ IL-9-expressiong cells among Th9 polarised UC lymphocytes. 
Among polarised cells, about $25 \%$ of the $\mathrm{IRF}^{+}{ }^{+}$cells expressed IL-9. We confirmed CD3, IL-9 and IRF4 colocalisation in situ by confocal imaging consistent with the idea that IRF4 acts as a key transcription factor for the generation of IL-9 in the inflamed gut of patients with UC.

In mice, Th9 cells can produce IL-9 and IL-10. ${ }^{16}{ }^{17}$ Moreover, invariable NKT-derived IL-9 has been shown to protect animals in a mouse model of colitis in an IL-4-dependent manner. ${ }^{24}$ We addressed this scenario in patients with UC and found that lamina propria cells from patients with UC did not express IL-9 and IL-10 strengthening the point that human Th9 cells do not coexpress IL-10. ${ }^{34} 35$ Since invariable NKT cells from the lamina propria of patients with UC did not express IL-9, and IL-4 was not coexpressed with IL-9 in our setting, the observed results ${ }^{24}$ could be explained by differences between iNKT cells from humans and mice.

We next focused on the ability of peripheral blood lymphocytes from patients with UC to produce IL-9. Stimulated cells produced significantly higher levels of IL-9 compared with unstimulated cells from the same patients with UC. Moreover, lymphocytes from patients with UC with $\mathrm{C}$ reactive protein levels $>5 \mathrm{mg} / \mathrm{L}$ produced significantly more IL-9 compared with those from patients with levels $<5 \mathrm{mg} / \mathrm{L}$, suggesting that IL-9 levels might potentially represent a systemic inflammatory marker along with $\mathrm{C}$ reactive protein or S100A8 in UC. ${ }^{1}$ Moreover, UC lymphocytes produced increased levels of IL-10, IL-13, IL-17A, TGF- $\beta$ and to a lesser extent IL-4. However, except for IL-13 and IL-10 whose levels moderately correlated with those of IL-9, we found no further correlations between IL-9 levels and levels of the other investigated cytokines. In line with our results, recent studies found that human Th9 cells do not produce IL-10 or signature cytokines of the other Th subsets whereas IL-9 production precedes and coordinates the secretion of other cytokines in cultured human lymphocytes. $^{34} 35$ Having identified a peripheral source of IL-9-expressing cells, we further wondered whether these cells have the potential to home to the gut by investigating their surface expression of $\alpha 4$ and $\beta 7$ integrins, two regulators of lymphocyte trafficking into the colon. ${ }^{37}$ About $16 \%$ and $30 \%$ of the $\mathrm{CD}^{+} \alpha 4^{+}$and $\mathrm{CD}^{+} \beta 7^{+}$cells, respectively expressed IL-9. Taken together these data indicate that in human UC IL-9 is mainly produced by $\mathrm{CD}^{+}$cells which are distinct from their murine counterparts with respect to IL-4 and IL-10 production. Nevertheless, our findings might be clinically relevant when targeting the recruitment of the IL-9-expressing cells by the use of therapeutic anti-integrin antibodies. ${ }^{38} 39$

The role of granulocytes in UC has been conclusively demonstrated: these cells and their derived products including proteases, reactive oxygen species and chemokines are present in high numbers in the inflamed gut and are a common feature of crypt abscesses, particularly during disease flare-ups. ${ }^{1}$ However, the fine molecular mechanisms governing the actions of these short-lived cells in UC still need further characterisation. The presence of the IL-9R on PMN has been discussed controversially. A first study reported that PMN express IL-9R mRNA, ${ }^{40}$ whereas a later one stated that PMN were not capable to do so. ${ }^{41}$ Subsequently, it was shown that peripheral blood PMN from patients with asthma express IL-9R mRNA in significantly higher amounts compared with PMN from healthy controls. ${ }^{25}$ The authors found that lung infiltrating PMN also stained positive for the IL-9R and by showing that IL-9 specifically induced IL-8 production in a dose-dependent manner, they demonstrated its functional role. ${ }^{25}$ Accordingly, our flow cytometry demonstrated that IL-9R is significantly overexpressed on the surface of circulating PMN from patients with UC as compared with control cells. Upon stimulation with either GM-CSF or IL-9, patients' PMN released high amounts of the antiapoptotic chemokine IL-8. IL-8 production proved to be dependent on the IL-9 concentration and anti-hIL-9R antibodies could block IL-8 release. In addition, our immunofluorescence two-colour stainings for myeloperoxidase and IL-9R in mucosa from patients with UC demonstrated that infiltrating PMN keep on expressing IL-9R, providing a possibly highly relevant and totally unanticipated functional mechanism for the PMN-mediated gut pathology in situ. We hypothesised that PMN encountering the proinflammatory milieu-for example, GM-CSF, ${ }^{42}$ TNF- $\alpha^{43}$ and IL-9 among others-in the gut of patients with UC become apoptosis-resistant. By producing more IL-8, PMN further increase their half-life ${ }^{43}$ and reinforce the recruitment of additional leucocytes to support chronic inflammation and establish crypt abscesses. To test our hypothesis experimentally, we incubated PMN with IL-9 and observed a dose-dependent inhibition of apoptosis. Moreover, this correlated with the ability of IL- 9 to induce IL- 8 production in PMN cultures suggesting that in UC the antiapoptotic effect of IL- 9 could be due to its ability to trigger IL- 8 production. $^{44}$

We further hypothesised that IL-9 actions on IL-9R-bearing gut epithelial cells are comparable with those on IL-9R-bearing lung epithelial cells. ${ }^{45}$ Indeed, epithelial cells from severe lesions of patients with UC expressed higher IL-9R levels than controls. Flow cytometry analysis of isolated epithelial cells indicated the presence of IL-9R on epithelial cells whereas intraepithelial $\mathrm{CD}^{+} \mathrm{T}$ cells showed only marginal expression. To functionally address the role of the IL-9R signalling in gut epithelial cells, we stimulated freshly isolated epithelial cells with IL-9 and performed intracellular staining for pSTAT5, a main signalling partner of the IL-9R. ${ }^{46}$ Interestingly, pSTAT5 was significantly increased in IL-9 versus non-stimulated cells. Preblocking IL-9R signalling resulted in decreased pSTAT5 levels. To functionally address the role of IL- 9 in the process of mucosal healing that accompanies epithelial gut restoration, we evaluated its effect on Caco- 2 cell monolayers. ${ }^{47}$ IL-9 significantly delayed the growth of the Caco- 2 cells into the gap in scratch assays. Taken together these results indicate that IL-9 signalling may activate epithelial cells in the UC lesions and block the restitution of the gut epithelium in established lesions.

Based on our present results we propose the following scenario triggered by IL-9 in UC: IL-9 produced by CD3 ${ }^{+}$T cells in the inflamed gut activates either one or more of the following pathways: (1) epithelial cells' activation by pSTAT5-mediated signalling in IL-9R overexpressing cells which may release proinflammatory cytokines to recruit leucocytes in situ; (2) activation of infiltrating PMN followed by the inhibition of their apoptosis. Long-lived PMN could reinforce further recruitment of activated lymphocytes ${ }^{48}$ and eosinophils ${ }^{49}$ by producing more IL- 8 and/or may directly damage the gut epithelium by releasing reactive oxygen species, matrix metalloproteinases and various cytokines including IL-9 itself; (3) IL-9 may block the mucosal healing process leading to the perpetuation of the inflammation and the establishment of chronic lesions.

In conclusion, our study demonstrates that IL-9 has pleiotropic functions in UC by inducing STAT5 signalling in gut epithelial cells, interfering with the mucosal healing process, inducing IL-8 production and increasing resistance to apoptosis in PMN. Alongside other potential cytokine targets, ${ }^{30}$ our results strongly recommend IL-9 as a possible disease severity marker and a promising future therapeutic candidate in UC. 


\section{Author affiliations}

${ }^{1}$ Department of Medicine 1, University of Erlangen-Nuremberg, Erlangen, Germany

${ }^{2}$ Molecular Biology Center, Interdisciplinary Research Institute on Bio-Nano-Sciences, Cluj-Napoca, Romania

${ }^{3}$ Department of Biology, Babes-Bolyai University, Cluj-Napoca, Romania

${ }^{4}$ Department of Dermatology, Laboratory of Dendritic Cell Biology, University of Erlangen-Nuremberg, Erlangen, Germany

5 Institute of Pathology, University of Erlangen-Nuremberg, Erlangen, Germany

${ }^{6}$ Department of Surgery, University of Regensburg, Regensburg, Germany

${ }^{7}$ Department of Gastroenterology, Sana Clinic, Ostholstein, Germany

Acknowledgements The authors thank Markus F Neurath, Department of Medicine 1, University of Erlangen-Nuremberg, Erlangen, Germany, for helpful discussion.

Contributors Conceived and designed experiments: NN, MTC, EP, CL, CB, JM. Performed experiments: NN, MTC, EP, CL, TR, RA, EK, GH, SF-F, AH, JM. Analysed data: NN, MTC, EP, CL, CB, JM. Wrote the paper: NN, MTC, JM. All authors critically read and approved the final version of the manuscript.

Funding This work was supported by grants from the Deutsche Forschungsgemeinschaft MU 3182/1-1 and DFG KFO257 (CB, JM) and the Romanian National University Research Council—PNII Idei PCCE-129/2008. MTC received financial support from the Sectoral Operational Programme for Human Resources Development 2007-2013 cofinanced by the European Social Fund under the project number POSDRU 89/1.5/S/61104. JM was supported by a grant from the Broad Medical Research Program of the Broad Foundation IBD-0200R2.

\section{Competing interests None.}

Patient consent Obtained.

Ethics approval Local Ethical Committee and the Review Board of the University of Erlangen-Nuremberg (\# 4032/KFO/2011; 4032/2009).

Provenance and peer review Not commissioned; externally peer reviewed.

\section{REFERENCES}

1 Danese S, Fiocchi C. Ulcerative colitis. N Engl J Med 2011;365:1713-25.

2 Kaser A, Zeissig S, Blumberg RS. Inflammatory bowel disease. Annu Rev Immunol 2010;28:573-621.

3 Neurath MF. Animal models of inflammatory bowel diseases: illuminating the pathogenesis of colitis, ileitis and cancer. Dig Dis 2012;30(Suppl 1):91-4.

4 Neurath MF, Fuss I, Kelsall BL, et al. Antibodies to interleukin 12 abrogate established experimental colitis in mice. J Exp Med 1995;182:1281-90.

5 Heller F, Florian P, Bojarski C, et al. Interleukin-13 is the key effector Th2 cytokine in ulcerative colitis that affects epithelial tight junctions, apoptosis, and cell restitution. Gastroenterology 2005;129:550-64.

6 Heller F, Fuss IJ, Nieuwenhuis EE, et al. Oxazolone colitis, a Th2 colitis model resembling ulcerative colitis, is mediated by IL-13-producing NK-T cells. Immunity 2002;17:629-38.

7 Korn T, Bettelli E, Oukka M, et al. IL-17 and Th17 Cells. Annu Rev Immunol 2009;27:485-517.

8 Mosmann TR, Cherwinski H, Bond MW, et al. Two types of murine helper T cell clone. I. Definition according to profiles of lymphokine activities and secreted proteins. J Immunol 1986:136:2348-57.

9 Mosmann TR, Coffman RL. TH1 and TH2 cells: different patterns of lymphokine secretion lead to different functional properties. Annu Rev Immunol 1989;7:145-73.

10 Hundorfean G, Neurath MF, Mudter J. Functional relevance of T helper 17 (Th17) cells and the IL-17 cytokine family in inflammatory bowel disease. Inflamm Bowel Dis 2012;18:180-6.

11 Kobayashi T, Okamoto S, Hisamatsu T, et al. IL23 differentially regulates the Th1/ Th17 balance in ulcerative colitis and Crohn's disease. Gut 2008:57:1682-9.

12 Kaplan MH. Th9 cells: differentiation and disease. Immunol Rev 2013;252:104-15.

13 Eyerich S, Eyerich K, Pennino D, et al. Th22 cells represent a distinct human T cell subset involved in epidermal immunity and remodeling. I Clin Invest 2009;119:3573-85

14 Wilhelm C, Hirota K, Stieglitz B, et al. An IL-9 fate reporter demonstrates the induction of an innate IL-9 response in lung inflammation. Nat Immunol 2011:12:1071-7.

15 Wilhelm C, Turner JE, Van Snick J, et al. The many lives of IL-9: a question of survival? Nat Immunol 2012:13:637-41.

16 Dardalhon V, Awasthi A, Kwon H, et al. IL-4 inhibits TGF-beta-induced Foxp3+ T cells and, together with TGF-beta, generates IL-9+ IL-10+ Foxp3(-) effector T cells. Nat Immunol 2008:9:1347-55.

17 Veldhoen M, Uyttenhove C, van Snick J, et al. Transforming growth factor-beta 'reprograms' the differentiation of T helper 2 cells and promotes an interleukin 9-producing subset. Nat Immunol 2008;9:1341-6.
18 Goswami R, Jabeen $R$, Yagi $R$, et al. STAT6-dependent regulation of Th9 development. J Immunol 2012:188:968-75.

19 Staudt $\mathrm{V}$, Bothur E, Klein $\mathrm{M}$, et al. Interferon-regulatory factor 4 is essential for the developmental program of T helper 9 cells. Immunity 2010;33:192-202.

20 Chang HC, Sehra S, Goswami R, et al. The transcription factor PU.1 is required for the development of IL-9-producing T cells and allergic inflammation. Nat Immunol 2010;11:527-34

21 Mudter J, Amoussina L, Schenk M, et al. The transcription factor IFN regulatory factor-4 controls experimental colitis in mice via T cell-derived IL-6. J Clin Invest 2008;118:2415-26.

22 Mudter J, Yu J, Zufferey C, et al. IRF4 regulates IL-17A promoter activity and controls RORgammat-dependent Th17 colitis in vivo. Inflamm Bowel Dis 2011:17:1343-58.

23 Gupta RB, Harpaz N, Itzkowitz S, et al. Histologic inflammation is a risk factor for progression to colorectal neoplasia in ulcerative colitis: a cohort study. Gastroenterology 2007;133:1099-105; quiz 340-1.

24 Kim HS, Chung DH. IL-9-producing invariant NKT cells protect against DSS-induced colitis in an IL-4-dependent manner. Mucosal Immunol 2013;6:347-57.

25 Abdelilah S, Latifa K, Esra N, et al. Functional expression of IL-9 receptor by human neutrophils from asthmatic donors: role in IL-8 release. J Immunol 2001;166:2768-74.

26 Amulic B, Cazalet $C$, Hayes $\mathrm{GL}$, et al. Neutrophil function: from mechanisms to disease. Annu Rev Immunol 2012;30:459-89.

27 Danese $\mathrm{S}$. New therapies for inflammatory bowel disease: from the bench to the bedside. Gut 2012:61:918-32.

28 Schett $G$, Elewaut $D$, Mclnnes IB, et al. How Cytokine Networks Fuel Inflammation: toward a cytokine-based disease taxonomy. Nat Med 2013;19:822-4.

29 Fischer A, Gluth M, Pape UF, et al. Adalimumab prevents barrier dysfunction and antagonizes distinct effects of TNF-alpha on tight junction proteins and signaling pathways in intestinal epithelial cells. Am I Physiol Gastrointest Liver Physiol 2013:304:G970-9.

30 Macdonald TT, Biancheri P, Sarra M, et al. What's the next best cytokine target in IBD? Inflamm Bowel Dis 2012;18:2180-9.

31 Coffman RL. Origins of the $\mathrm{T}(\mathrm{H}) 1-\mathrm{T}(\mathrm{H}) 2$ model: a personal perspective. Nat Immunol 2006;7:539-41.

32 Manolakis AC, Kapsoritakis AN, Tiaka EK, et al. Calprotectin, calgranulin C, and other members of the 1100 protein family in inflammatory bowel disease. Dig Dis Sci 2011:56:1601-11.

33 McNamara PS, Flanagan BF, Baldwin LM, et al. Interleukin 9 production in the lungs of infants with severe respiratory syncytial virus bronchiolitis. Lancet 2004;363:1031-7.

34 Putheti P, Awasthi A, Popoola J, et al. Human CD4 memory T cells can become CD4+IL-9+ T cells. PloS ONE 2010;5:e8706.

35 Schlapbach C, Gehad A, Yang C, et al. Human TH9 cells are skin-tropic and have autocrine and paracrine proinflammatory capacity. Sci Trans/ Med 2014;6:219ra8.

36 Wong MT, Ye JJ, Alonso MN, et al. Regulation of human Th9 differentiation by type I interferons and IL-21. Immunol Cell Biol 2010;88:624-31.

37 Souza HS, Elia CC, Spencer J, et al. Expression of lymphocyte-endothelial receptor-ligand pairs, alpha4beta7/MAdCAM-1 and OX40/OX40 ligand in the colon and jejunum of patients with inflammatory bowel disease. Gut 1999;45:856-63.

38 Feagan BG, Greenberg GR, Wild G, et al. Treatment of ulcerative colitis with a humanized antibody to the alpha4beta7 integrin. $N$ Engl I Med 2005;352:2499-507.

39 Neurath MF. New targets for mucosal healing and therapy in inflammatory bowel diseases. Mucosal Immunol 2014;7:6-19.

40 Chang MS, Engel G, Benedict $C$, et al. Isolation and characterization of the human interleukin-9 receptor gene. Blood 1994;83:3199-205.

41 Girard D, Boiani N, Beaulieu AD. Human neutrophils express the interleukin-15 receptor alpha chain (IL-15Ralpha) but not the IL-9Ralpha component. Clin Immunol Immunopathol 1998:88:232-40.

42 Lampinen M, Sangfelt $P$, Taha $Y$, et al. Accumulation, activation, and survival of neutrophils in ulcerative colitis: regulation by locally produced factors in the colon and impact of steroid treatment. Int J Colorectal Dis 2008;23:939-46.

43 Mantovani A, Cassatella MA, Costantini $C$, et al. Neutrophils in the activation and regulation of innate and adaptive immunity. Nat Rev Immunol 2011;11:519-31.

44 Klein JB, Rane MJ, Scherzer JA, et al. Granulocyte-macrophage colony-stimulating factor delays neutrophil constitutive apoptosis through phosphoinositide 3-kinase and extracellular signal-regulated kinase pathways. J Immunol 2000;164:4286-91.

45 Dong Q, Louahed J, Vink A, et al. IL-9 induces chemokine expression in lung epithelial cells and baseline airway eosinophilia in transgenic mice. Eur J Immunol 1999:29:2130-9.

46 Knoops L, Renauld JC. IL-9 and its receptor: from signal transduction to tumorigenesis. Growth Factors 2004;22:207-15.

47 Hubatsch I, Ragnarsson EG, Artursson P. Determination of drug permeability and prediction of drug absorption in Caco-2 monolayers. Nat Protoc 2007:2:2111-19.

48 Gesser B, Lund M, Lohse N, et al. IL-8 induces T cell chemotaxis, suppresses IL-4, and up-regulates IL-8 production by CD4+ T cells. J Leukoc Biol 1996;59:407-11.

49 Erger RA, Casale TB. Interleukin-8 is a potent mediator of eosinophil chemotaxis through endothelium and epithelium. Am J Physiol 1995;268:L117-22. 


\section{GUT IL-9 and its receptor are predominantly involved in the pathogenesis of UC}

Nancy Nalleweg, Mircea Teodor Chiriac, Eva Podstawa, Christian Lehmann, Tilman T Rau, Raja Atreya, Ekaterina Krauss, Gheorghe Hundorfean, Stefan Fichtner-Feigl, Arndt Hartmann, Christoph Becker and Jonas Mudter

Gut 2015 64: 743-755 originally published online June 23, 2014 doi: 10.1136/gutjnl-2013-305947

Updated information and services can be found at:

http://gut.bmj.com/content/64/5/743

These include:

Supplementary Material

Supplementary material can be found at:

http://gut.bmj.com/content/suppl/2014/06/23/gutjnl-2013-305947.DC1. html

References This article cites 49 articles, 12 of which you can access for free at: http://gut.bmj.com/content/64/5/743\#BIBL

Email alerting

Receive free email alerts when new articles cite this article. Sign up in the service box at the top right corner of the online article.

\section{Notes}

To request permissions go to:

http://group.bmj.com/group/rights-licensing/permissions

To order reprints go to:

http://journals.bmj.com/cgi/reprintform

To subscribe to BMJ go to:

http://group.bmj.com/subscribe/ 